Review

\title{
Control of Spin-Crossover Phenomena in One-Dimensional Triazole-Coordinated Iron(II) Complexes by Means of Functional Counter Ions
}

\author{
Akira Sugahara $^{1}$ (D), Hajime Kamebuchi ${ }^{2}$, Atsushi Okazawa ${ }^{3}$ (D), Masaya Enomoto ${ }^{2}$ \\ and Norimichi Kojima ${ }^{3,4, *}$ \\ 1 Department of Chemical System Engineering, Faculty of Engineering, The University of Tokyo, Hongo 7-3-1, \\ Bunkyo-ku, Tokyo 113-8656, Japan; a_sugahara@battery.t.u-tokyo.ac.jp \\ 2 Department of Chemistry, Faculty of Science Division I, Tokyo University of Science, Kagurazaka 1-3, \\ Shinjuku-ku, Tokyo 162-8601, Japan; hkamebuchi@rs.tus.ac.jp (H.K.); menomoto@rs.kagu.tus.ac.jp (M.E.) \\ 3 Graduate School of Arts and Sciences, The University of Tokyo, Komaba 3-8-1, Meguro-ku, Tokyo 153-8902, \\ Japan; cokazawa@mail.ecc.u-tokyo.ac.jp \\ 4 Toyota Physical and Chemical Research Institute, Yokomichi 41-1, Nagakute-shi, Aichi 480-1192, Japan \\ * Correspondence: kojima@toyotariken.jp or cnori@mail.ecc.u-tokyo.ac.jp; \\ Tel.: +81-561-57-9593; Fax: +81-561-63-6302
}

Received: 23 June 2017; Accepted: 16 July 2017; Published: 19 August 2017

\begin{abstract}
The spin-crossover (SCO) phenomenon between a high-spin and a low-spin state has attracted much attention in the field of materials science. Among the various kinds of SCO complexes, the triazole-bridged iron(II) polymeric chain system, $\left[\mathrm{Fe}(\mathrm{II})(\mathrm{R}-\mathrm{trz})_{3}\right] \mathrm{X}_{2} \cdot x \mathrm{H}_{2} \mathrm{O}$ (where trz is triazole and $\mathrm{X}$ is the anion), exhibiting the SCO phenomenon with thermal hysteresis around room temperature, has been extensively studied from the viewpoint of molecular memory and molecular devices. In connection with this system, we have controlled the SCO phenomenon according to the characteristic properties of counter ions. In the case of $\mathrm{X}$ being $\mathrm{C}_{n} \mathrm{H}_{2 n+1} \mathrm{SO}_{3}{ }^{-}$, the spin transition temperature $\left(T_{1 / 2}\right)$ increases with increasing the length $(n)$ of the alkyl chain of the counter ion and saturates above $n=5$, which is attributed to the increase in the intermolecular interaction of the alkyl chains of $\mathrm{C}_{n} \mathrm{H}_{2 n+1} \mathrm{SO}_{3}{ }^{-}$, called the fastener effect. The hysteresis width of $T_{1 / 2}$ decreases with increasing $n$, showing the even-odd, also known as parity, effect. In the cases where $\mathrm{X}$ is toluenesulfonate (tos: $\mathrm{CH}_{3} \mathrm{C}_{6} \mathrm{H}_{4} \mathrm{SO}_{3}{ }^{-}$) and aminobenzenesulfonate (abs: $\mathrm{NH}_{2} \mathrm{C}_{6} \mathrm{H}_{4} \mathrm{SO}_{3}{ }^{-}$), $T_{1 / 2}$ and its hysteresis width vary drastically with the structural isomerism (ortho-, metha-, and para-substitution) of counter ions, which implies the possibility of photoinduced spin transition by means of the photoisomerization of counter ions. From this strategy, we have synthesized [Fe(II) $\left.\left(\mathrm{NH}_{2} \text {-trz }\right)_{3}\right](\mathrm{SP} 150)_{2} \cdot 2 \mathrm{H}_{2} \mathrm{O}(\mathrm{SP} 150=$ $\mathrm{N}$-alkylsulfonated spiropyran) and investigated the SCO phenomenon. Moreover, we have developed $\left[\mathrm{Fe}(\mathrm{II})(\mathrm{R} \text {-trz) })_{3} \mathrm{ONafion}\right.$ films exhibiting spin transition around room temperature, where the Nafion membrane behaves as a counter anion as well as a transparent substrate, and investigated the photogenerated high-spin state below $35 \mathrm{~K}$. The lifetime of the photogenerated high-spin state strongly depends on the intensity of irradiated light.
\end{abstract}

Keywords: multifunctionality; spin-crossover; isomerization effect; fastener effect; Nafion; transition metal complex film; LIESST

\section{Introduction}

An octahedrally coordinated transition metal ion, having an electron configuration of $3 \mathrm{~d}^{n}(n=4-7)$, exhibits the possibility to change the ground spin state between the low-spin (LS) and high-spin (HS) states. Switching between the LS and HS states is known as the spin-crossover (SCO) phenomenon, 
which can be controlled by external stimuli such as heat, applied pressure, and light irradiation. The first SCO phenomenon was observed in the tris(dithiocarbamato)iron(III) family, [Fe(III) $\left.\left(\mathrm{S}_{2} \mathrm{CNR}_{2}\right)_{3}\right]$ ( $\mathrm{R}=\mathrm{C}_{n} \mathrm{H}_{2 n+1}$ etc.), reported by Cambi et al. in the 1930s [1]. Since then, a huge number of SCO complexes containing $3 \mathrm{~d}^{n}(n=4-7)$ metal ions have been developed [2].

From the viewpoint of molecular devices and optical information storage, the SCO phenomenon has gained renewed importance since the discovery in 1984 of photoinduced LS-HS transition for [Fe(II)(ptz) $\left.)_{6}\right]\left(\mathrm{BF}_{4}\right)_{2}$ (ptz is 1-propyltetrazole) [3]. This photoinduced SCO phenomenon has been named LIESST (Light-Induced Excited Spin State Trapping). The LIESST mechanism is a light-induced conversion from the ground LS state $\left({ }^{1} \mathrm{~A}_{1 \mathrm{~g}}\right)$ to the lowest HS state $\left({ }^{5} \mathrm{~T}_{2 \mathrm{~g}}\right)$, which was proposed by Decurtins et al., involving the first intersystem crossing step with $\Delta S=1$ from the initially excited ${ }^{1} \mathrm{~T}_{1 \mathrm{~g}}$ state to the lower lying ${ }^{3} \mathrm{~T}_{1 \mathrm{~g}}$ state. In the second intersystem crossing step with $\Delta S=1$, the system has a possibility to drop into the lowest HS state of ${ }^{5} \mathrm{~T}_{2 \mathrm{~g}}$, and it remains trapped at sufficiently low temperatures because of the potential barrier between the ${ }^{5} \mathrm{~T}_{2 \mathrm{~g}}$ and ${ }^{1} \mathrm{~A}_{1 \mathrm{~g}}$ states [4]. Being stimulated by the discovery of LIESST for [Fe(II)(ptz) 6 ] $\left(\mathrm{BF}_{4}\right)_{2}$, various kinds of SCO complexes showing LIESST have been studied for mainly iron(II) and iron(III) complexes [5].

For the application of the SCO phenomenon to molecular devices, an SCO complex, [Fe(II)(H-trz $\left.)_{2.85}\left(\mathrm{NH}_{2} \text {-trz }\right)_{0.15}\right]\left(\mathrm{ClO}_{4}\right)_{2} \cdot \mathrm{H}_{2} \mathrm{O}$ (R-trz is 4-R-1,2,4-triazole), exhibiting a thermally induced spin transition with large thermal hysteresis around room temperature, was synthesized in 1993 [6]. Over the past two decades, one-dimensional (1D) iron(II) coordination polymers bridged by 4-substituted-1,2,4-triazole (R-trz) (Figure 1) have provided many kinds of extended systems [7]. The general formula of these complexes is described as $\left[\mathrm{Fe}(\mathrm{II})(\mathrm{R}-\operatorname{trz})_{3}\right]$ Anion $\cdot x \mathrm{H}_{2} \mathrm{O}$, where Anion is a mono- or divalent anion. The materials are applicable to molecular electronics or sensors [8,9] because their SCO phenomena are abrupt and tunable, and sometimes associated with wide thermal hysteresis around room temperature. In this system, these SCO characteristics vary depending on three factors: (i) substituents (R) on triazole ligands; (ii) non-coordinated anions located in the voids in $1 \mathrm{D}$ chains; and (iii) interstitial crystal water molecules which form hydrogen bonds with the ligands. An excellent example of controlling the transition temperature $\left(T_{1 / 2}\right)$ was demonstrated by Kahn et al. based on a concept called "molecular alloy" [6]. The alloy compounds [Fe(II)(H-trz) $\left.)_{3-3 x}\left(\mathrm{NH}_{2} \text {-trz }\right)_{3 x}\right]\left(\mathrm{ClO}_{4}\right)_{2} \cdot y \mathrm{H}_{2} \mathrm{O}$ show a linear variation of $T_{1 / 2} \uparrow$ and $T_{1 / 2} \downarrow$ as a function of $x$, where $T_{1 / 2} \uparrow$ and $T_{1 / 2} \downarrow$ stand for the temperatures at the HS and LS ratio of 50:50 on the heating and cooling processes, respectively. Another kind of alloy involves mixed counter anions, the formula of which is $\left[\mathrm{Fe}(\mathrm{III})\left(\mathrm{NH}_{2} \text {-trz }\right)_{3}\right]\left(\mathrm{NO}_{3}\right)_{2 x}\left(\mathrm{BF}_{4}\right)_{2-2 x} \cdot y \mathrm{H}_{2} \mathrm{O}$ [10]. Thus, the spin transition behavior is finely tunable to serve molecular devices working at room temperature due to optical and magnetic bistabilities. Furthermore, the LIESST effect was also reported for [Fe(II)(R-trz) $\left.)_{3}\right]$ complexes as seen in typical SCO complexes [11].
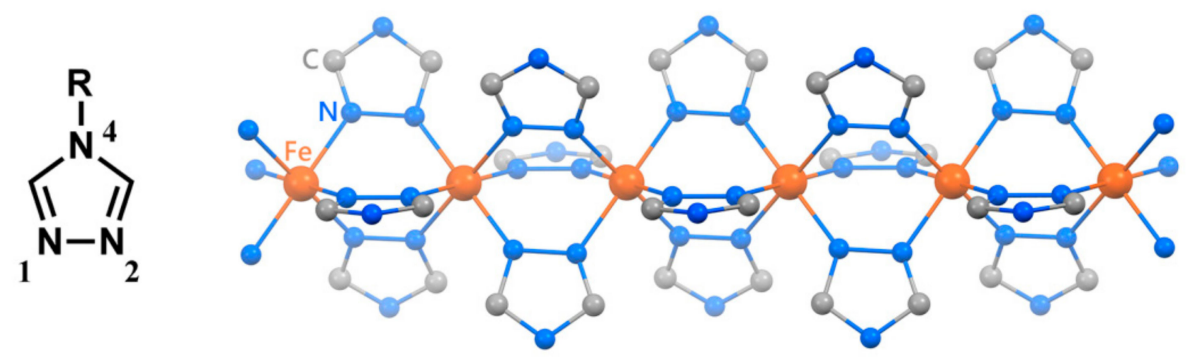

Figure 1. Molecular structure of 4-R-1,2,4-triazole (left) and one-dimensional (1D) coordination polymer chains of $\left[\mathrm{Fe}(\mathrm{II})(\mathrm{R}-\mathrm{trz})_{3}\right]$ (right). Hydrogen atoms and substituents (R) are omitted for clarity.

In order to create molecular devices, a preparation of single crystals or a transparent film is more suitable for memory or display, respectively, than powder conditions. However, single crystals for the $\left[\mathrm{Fe}(\mathrm{II})(\mathrm{R}-\mathrm{trz})_{3}\right] \mathrm{X}_{2} \cdot x \mathrm{H}_{2} \mathrm{O}$ family have never been created, except for the single crystal $\mathrm{X}$-ray diffraction 
study on $\left[\mathrm{Fe}(\mathrm{II})\left(\mathrm{NH}_{2} \text {-trz }\right)_{3}\right]\left(\mathrm{NO}_{3}\right)_{2}$ in 2011 [12]. Furthermore, the [Fe(II)(R-trz $\left.)_{3}\right] \mathrm{X}_{2} \cdot x \mathrm{H}_{2} \mathrm{O}$ family has low solubility. By increasing the solubility of the organic solvent, the $\left[\mathrm{Fe}(\mathrm{II})(\mathrm{R}-\mathrm{trz})_{3}\right]$ complex is able to be applied to solution processes, such as the spin coating method, the spray method, and so on. Therefore, various approaches to manipulating the processes of using triazole complexes were reported. One of the approaches is the modification of triazole ligands by substituting the long alkyl groups. Substituting the triazole complexes with long alkyl groups (octadecyl [13], 3-dodecyloxy propyl [14]) was reported. Another modification of the triazole ligand is the construction of the dendrimer by substituting it with the dendrons of a benzyl ether-type unit [14-17]. Another approach is embedding the complex in a polymer matrix, such as polystyrene [18], polymethyl methacrylate [19,20], or Nafion [21-23].

In connection with the $\left[\mathrm{Fe}(\mathrm{II})(\mathrm{R}-\mathrm{trz})_{3}\right] \mathrm{X}_{2}$ system, we controlled the SCO phenomena by using the characteristic properties of counter anions. In the case when $\mathrm{X}$ is toluenesulfonate (tos: $\mathrm{CH}_{3} \mathrm{C}_{6} \mathrm{H}_{4} \mathrm{SO}_{3}{ }^{-}$) and aminobenzenesulfonate (abs: $\mathrm{NH}_{2} \mathrm{C}_{6} \mathrm{H}_{4} \mathrm{SO}_{3}{ }^{-}$), $T_{1 / 2}$ and its hysteresis width vary drastically with the structural isomerism (substitution at the $o_{-}, m_{-}$, and $p$-positions on the benzene ring of tos and abs) [24,25], which implies the possibility of photoinduced spin transition by means of the photoisomerization of counter ions. Based on this strategy, we synthesized [Fe(II)( $\mathrm{NH}_{2}$-trz) $)_{3}$ (SP150) $)_{2} \cdot 2 \mathrm{H}_{2} \mathrm{O}$ (SP150 is $\mathrm{N}$-alkylsulfonated spiropyran) and investigated the SCO phenomenon [26]. In the case where $\mathrm{X}$ is $\mathrm{C}_{n} \mathrm{H}_{2 n+1} \mathrm{SO}_{3}{ }^{-}$, the $T_{1 / 2}$ increases with increasing the length (n) of the alkyl chain of the counter ion and saturates above $n=5$. This is attributed to the increase in the intermolecular interaction of the alkyl chains of $\mathrm{C}_{n} \mathrm{H}_{2 n+1} \mathrm{SO}_{3}{ }^{-}$, called the fastener effect [27]. The hysteresis width of $T_{1 / 2}$ decreases with increasing $n$, showing the even-odd (parity) effect, which is known for 1D iron(II) SCO coordination polymers based on bridging di-tetrazoles [28]. Moreover, we developed [Fe(II)(R-trz) $)_{3}$ @Nafion films exhibiting spin transition around room temperature, in which the Nafion membrane behaves as a counter anion as well as a transparent substrate [21], and investigated the condensed photogenerated HS state below $35 \mathrm{~K}$ [29]. The lifetime of the photogenerated HS state strongly depends on the intensity of irradiated light. In this paper, we review the effect of the characteristic properties of counter anions on the SCO behavior and the photoinduced SCO phenomenon for $\left[\mathrm{Fe}(\mathrm{II})(\mathrm{R}-\mathrm{trz})_{3}\right] \mathrm{X}_{2} \cdot x \mathrm{H}_{2} \mathrm{O}\left(\mathrm{R}=\mathrm{H}, \mathrm{NH}_{2}\right.$, etc.; $\mathrm{X}=$ anion), which has been mainly contributed by our group.

\section{The Effect of Crystal Solvent on SCO for the [Fe(II)(R-trz) $\left.{ }_{3}\right]$ System}

In the $\left[\mathrm{Fe}(\mathrm{II})\left(\mathrm{R}\right.\right.$-trz) $\left.{ }_{3}\right]$ chain system, not only are various kinds of counter anions acceptable, but also various crystal solvents, which remarkably influences the SCO phenomenon as well as other SCO complexes. As for the crystal solvent effect, there are some prominent reports on tris(2-picolylamine)iron(II) dichlorides, where the SCO behavior significantly depends on of the type of alcohol solvent [30] and the amount of crystal water [31]. In this section, we describe the effect of crystal water on the $\mathrm{SCO}$ for $\left[\mathrm{Fe}(\mathrm{II})\left(\mathrm{NH}_{2} \text {-trz }\right)_{3}\right](p \text {-tos })_{2} \cdot x \mathrm{H}_{2} \mathrm{O}$. In connection with $\left[\mathrm{Fe}(\mathrm{II})\left(\mathrm{NH}_{2} \text {-trz }\right)_{3}\right](p \text {-tos })_{2} \cdot 1.5 \mathrm{H}_{2} \mathrm{O}$, Codjvi and $\mathrm{Kahn}$ et al. reported the $\mathrm{SCO}$ transition with wide thermal hysteresis by means of optical spectroscopy [32]. According to them, in the first heating process $\left[\mathrm{Fe}(\mathrm{III})\left(\mathrm{NH}_{2} \text {-trz }\right)_{3}\right](p \text {-tos })_{2} \cdot 1.5 \mathrm{H}_{2} \mathrm{O}$ shows an abrupt spin transition accompanied by an apparent optical absorption change at $361 \mathrm{~K}$, and a wide thermal hysteresis width at $82 \mathrm{~K}$ was observed in the subsequent cooling process. In the second cycle, however, the spin transition in the heating process takes place at the much lower temperature of $296 \mathrm{~K}$. The thermogravimetric analysis revealed that the abrupt spin transition at $361 \mathrm{~K}$ in the heating process is induced by the dehydration of crystal water molecules. The reproducible spin transition of $T_{1 / 2} \uparrow=296 \mathrm{~K}$ and $T_{1 / 2} \downarrow=279 \mathrm{~K}$ with the hysteresis width of $17 \mathrm{~K}$ is attributed to that of anhydrous [Fe(II)( $\left.\left(\mathrm{NH}_{2} \text {-trz) }\right)_{3}\right](p \text {-tos })_{2}$.

In order to investigate the effect of crystal water on the SCO phenomenon for the $\left[\mathrm{Fe}(\mathrm{II})(\mathrm{R}-\mathrm{trz})_{3}\right]$ system, we prepared [Fe(II)( $\mathrm{NH}_{2}$-trz $\left.)_{3}\right](p \text {-tos })_{2} \cdot x \mathrm{H}_{2} \mathrm{O}$ for different values of $x: 1.5,3.5,5.5$, and 8 [33]. Although the number $(x)$ of crystal water nearly equals 1.5 under ambient humidity, $x$ increases from 1.5 under more humid conditions. To keep $x$ in the desired range above 1.5, the hydrated sample was sealed into an aluminum capsule after the determination of $x$ by means of thermogravimetry. For the 
extended X-ray absorption fine structure (EXAFS) measurements of $x=1.5$, the sample was diluted with boron nitride (BN) to create a pellet. In order to prevent the desorption of crystal water in a vacuum, the pellet was completely sealed with an adhesive substrate (Stycast No. 1266).

To prove the formation of a 1D Fe chain structure, [Fe(II) $\left.\left(\mathrm{NH}_{2}-\operatorname{trz}\right)_{3}\right]_{\infty}$, in $\left[\mathrm{Fe}(\mathrm{II})\left(\mathrm{NH}_{2}-\operatorname{trz}\right)_{3}\right]$ ( $p$-tos $)_{2} \cdot 1.5 \mathrm{H}_{2} \mathrm{O}$, we performed the Fe K-edge EXAFS spectra [33]. Figure 2 shows the Fourier transform of the spectra at 295 and $365 \mathrm{~K}$. The most intense peak, around $1.7 \AA$ in the Fourier transform, is derived from the Fe-N scattering. We found a remarkable peak at $7 \AA$, while in general, peaks are hardly observed in this region. The result indicates the existence of a linear arrangement of the Fe atoms, where enhanced multiple scattering can be observed as a significant peak in the long radius region [34]. The peak at about $7 \AA$ corresponds to the $\mathrm{Fe}-\mathrm{Fe}-\mathrm{Fe}$ multiple scattering, which proves the existence of a straight $1 \mathrm{D}$ Fe chain structure such as [Fe(II)(H-trz $\left.)_{2}(\operatorname{trz})\right]\left(\mathrm{BF}_{4}\right)$, where trz is 1,2,4-triazolate [35]. Reflecting the SCO transition, the peak positions at $365 \mathrm{~K}$ are clearly shifted to the longer side than those at $295 \mathrm{~K}$. The Fourier transform of EXAFS for [Fe(II) $\left.\left(\mathrm{NH}_{2} \text {-trz }\right)_{3}\right](p \text {-tos })_{2} \cdot 1.5 \mathrm{H}_{2} \mathrm{O}$ at $295 \mathrm{~K}$ and $365 \mathrm{~K}$ corresponds to the LS and HS states, respectively.

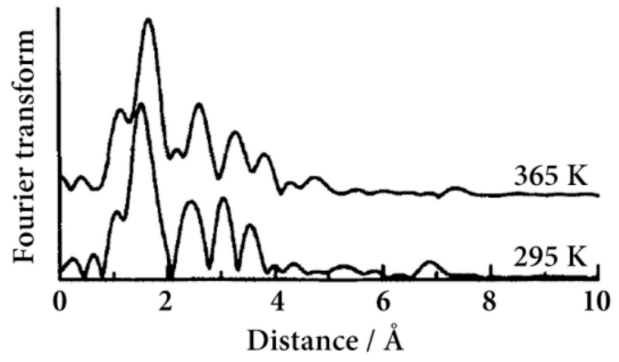

Figure 2. Fourier transforms of Fe K-edge extended X-ray absorption fine structure (EXAFS) oscillation function, $k^{3} \chi(k)$, for $\left[\mathrm{Fe}(\mathrm{II})\left(\mathrm{NH}_{2} \text {-trz }\right)_{3}\right](p \text {-tos })_{2} \cdot 1.5 \mathrm{H}_{2} \mathrm{O}$ at $295 \mathrm{~K}$ and $365 \mathrm{~K}$ [33].

Figure 3 shows the temperature dependence of the magnetic susceptibility multiplied by temperature $\left(\chi_{\mathrm{M}} T\right)$ for $\left[\mathrm{Fe}(\mathrm{II})\left(\mathrm{NH}_{2} \text {-trz }\right)_{3}\right](p \text {-tos })_{2} \cdot 1.5 \mathrm{H}_{2} \mathrm{O}$, indicating the stepwise SCO behavior. The intermediate plateau between 310 and $360 \mathrm{~K}$ increases with repeating the heating cycles, and the saturated $\chi_{M} T$ corresponds to the HS state. The disappearance of the intermediate state by repeating the heating cycles is thought to arise from the rearrangement of crystal water molecules by annealing. A similar irreversible thermal history of SCO behavior was reported on a Langmuir film of an amphiphilic iron(II) complex [36]. Owing to the rearrangement of crystal water molecules by annealing, we investigated the effect of crystal water on the SCO behavior for $\left[\mathrm{Fe}(\mathrm{II})\left(\mathrm{NH}_{2} \text {-trz }\right)_{3}\right](p \text {-tos })_{2} \cdot x \mathrm{H}_{2} \mathrm{O}$, where $x$ was $1.5,3.5,5.5$, and 8 , under the second heating cycle.

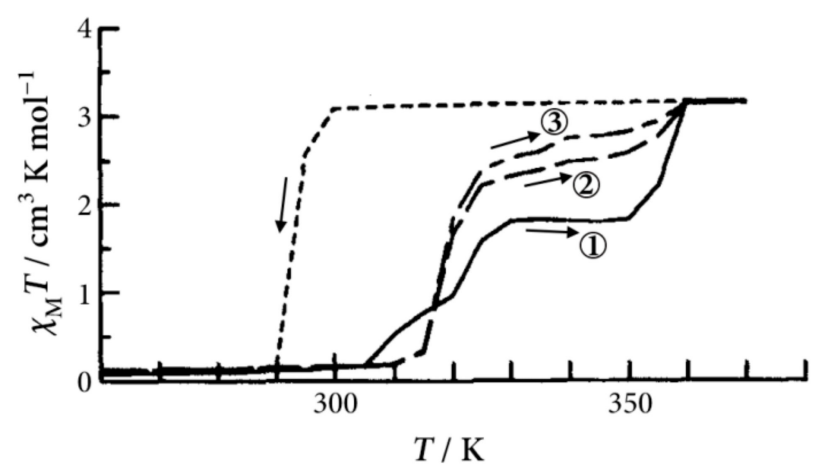

Figure 3. Temperature dependence of the magnetic susceptibility multiplied by temperature $\left(\chi_{\mathrm{M}} T\right)$ for $\left[\mathrm{Fe}(\mathrm{II})\left(\mathrm{NH}_{2} \text {-trz }\right)_{3}\right](p \text {-tos })_{2} \cdot 1.5 \mathrm{H}_{2} \mathrm{O}$. The solid line represents the first heating process, the broken line represents the second heating process, the dot-dashed line represents the third heating process, and the dotted line represents the cooling process. Reproduced with permission from Reference [33]. 
Figure 4 shows the SCO behavior for $\left[\mathrm{Fe}(\mathrm{II})\left(\mathrm{NH}_{2} \text {-trz }\right)_{3}\right](p \text {-tos })_{2} \cdot x \mathrm{H}_{2} \mathrm{O}$, where $x$ equals $1.5,3.5,5.5$, and 8 , under the second heating cycle. The samples where $x$ equals $1.5,3.5$, and 5.5 show a stepwise LS to HS transition, whereas the sample where $x$ is 8 shows a simple LS to HS transition with negligible thermal hysteresis. In the case where $x$ is 3.5, the temperature dependence of $\chi_{\mathrm{M}} T$ is equivalent to the superposition of $\chi_{\mathrm{M}} T$ between $x$ at 1.5 and $x$ at 5.5. As shown in Figure 4, with increasing the amount of crystal water, the transition temperature lowers and the thermal hysteresis width becomes narrow. This can be explained by the water molecules in $\left[\mathrm{Fe}(\mathrm{II})\left(\mathrm{NH}_{2} \text {-trz }\right)_{3}\right](p \text {-tos })_{2} \cdot x \mathrm{H}_{2} \mathrm{O}$ having two opposite functions in the SCO phenomenon. One is the formation of hydrogen bonding, which makes the lattice harder and stabilizes the LS state. The other function is behaving as a spacer between the $\left[\mathrm{Fe}(\mathrm{II})\left(\mathrm{NH}_{2} \text {-trz }\right)_{3}\right]$ chains, which makes the lattice softer and stabilizes the HS state. Therefore, with increasing the amount of crystal water, the function as a spacer becomes more dominant, which decreases $T_{1 / 2}$ and the hysteresis width. In the case where $x$ is 1.5 , the effect of the hydrogen bonding of crystal water molecules in the SCO phenomenon is the most dominant among the tests amounts of $x$ at $1.5,3.5,5.5$, and 8 . In connection with this, it should be mentioned that the effect of crystal water on the SCO transition is similar to that of the counter anions for [Fe(II) $\left.\left(\mathrm{NH}_{2}-\operatorname{trz}\right)_{3}\right]$ Anion $x \mathrm{H}_{2} \mathrm{O}$ [37-39]. With increasing the radius of the counter anion, the $T_{1 / 2}$ of the complex decreases. The results indicate that the counter anion acts as a spacer for the Fe chains. In addition, the anion with a larger radius makes the crystal lattice softer. Thus, the crystal water molecules and the counter anions both play an important role in the SCO behavior.

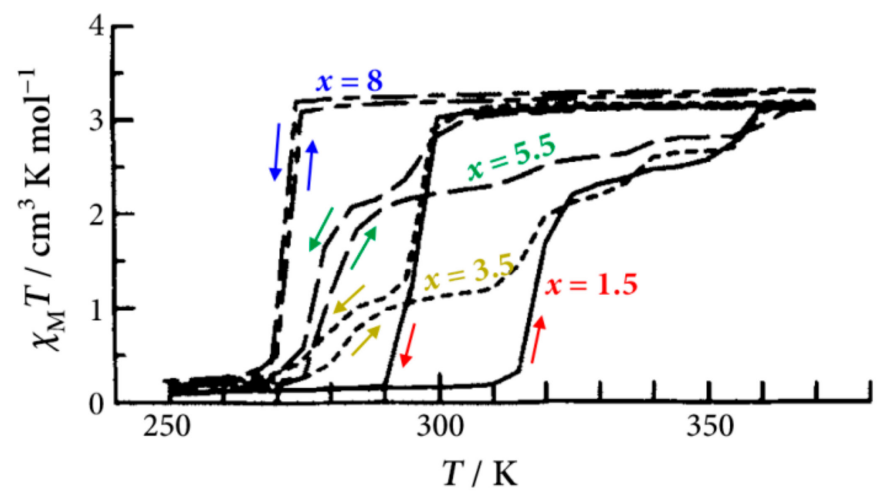

Figure 4. Temperature dependence of the magnetic susceptibility multiplied by temperature $\left(\chi_{\mathrm{M}} T\right)$ for $\left[\mathrm{Fe}(\mathrm{II})\left(\mathrm{NH}_{2} \text {-trz }\right)_{3}\right](p \text {-tos })_{2} \cdot x \mathrm{H}_{2} \mathrm{O} . x=1.5$ is represented by the solid line, $x=3.5$ is represented by the dotted line, $x=5.5$ is represented by the broken line, and $x=8$ is represented by the dot-dashed line. The arrows represent the sweeping directions of temperature. Reproduced with permission from Reference [33].

\section{The Effect of Structural Isomerism of Counter Ions on SCO for the [Fe(II)(R-trz) $\left.{ }_{3}\right]$ System}

In the case of spherical anions, isotropic structural changes affect the interchain interaction for $\left[\mathrm{Fe}(\mathrm{II})(\mathrm{R}-\mathrm{trz})_{3}\right] \mathrm{X}_{2} \cdot x \mathrm{H}_{2} \mathrm{O}$. Anisotropic structural changes, such as the structural isomerism of organic molecules, also affect the cooperative interaction among [ $\left.\mathrm{Fe}(\mathrm{II})\left(\mathrm{NH}_{2}-\operatorname{trz}\right)_{3}\right]$ chains. One of the structural isomers is an ortho-, meta-, and para-substituted benzene. In order to investigate the effect of structural isomerism of counter ions on the SCO phenomenon for the $\left[\mathrm{Fe}(\mathrm{II})(\mathrm{R}-\mathrm{trz})_{3}\right]$ system, we prepared $\left[\mathrm{Fe}(\mathrm{II})\left(\mathrm{NH}_{2} \text {-trz) }\right)_{3}\right](\text { tos })_{2} \cdot x \mathrm{H}_{2} \mathrm{O}$ and [Fe(II) $\left.\left(\mathrm{NH}_{2} \text {-trz) }\right)_{3}\right](\mathrm{abs})_{2} \cdot x \mathrm{H}_{2} \mathrm{O}[24,25]$. The amount of crystal water in $\left[\mathrm{Fe}(\mathrm{II})\left(\mathrm{NH}_{2} \text {-trz }\right)_{3}\right](\mathrm{tos})_{2} \cdot x \mathrm{H}_{2} \mathrm{O}$ was determined as $x=2,1.5$, and 1.5 for $o-, m-$, and $p$-tos salts, respectively. The amount of crystal water in $\left[\mathrm{Fe}(\mathrm{II})\left(\mathrm{NH}_{2}-\operatorname{trz}\right)_{3}\right](\mathrm{abs})_{2} \cdot x \mathrm{H}_{2} \mathrm{O}$ was $x=2$ for all the $o^{-}$, $m-$, and $p$-abs salts, obtained by means of thermogravimetric analysis. Figure 5 shows the molecular structures of $o^{-}, m-, p$-tos and $o_{-}, m-, p$-abs. 
tos<smiles>Cc1ccccc1S(=O)(=O)[O-]</smiles>

abs<smiles>Nc1ccccc1S(=O)(=O)[O-]</smiles><smiles>Cc1cccc(S(=O)(=O)[O-])c1</smiles>

$p-$<smiles>Cc1ccc(S(=O)(=O)[O-])cc1</smiles><smiles>Nc1cccc(S(=O)(=O)[O-])c1</smiles><smiles>Nc1ccc([S+](=O)(=O)[O-])cc1</smiles>

Figure 5. Molecular structures of $o-, m-$, and $p$-toluenesulfonate (tos) and $o-, m-$, and $p$ aminobenzenesulfonate (abs).

The temperature dependence on the magnetic susceptibility of $\left[\mathrm{Fe}(\mathrm{II})\left(\mathrm{NH}_{2}-\operatorname{trz}\right)_{3}\right](\operatorname{tos})_{2} \cdot x \mathrm{H}_{2} \mathrm{O}$ is shown in Figure 6 [24]. All the complexes show the spin transition around $300 \mathrm{~K}$. In the case of the $o$-tos salt, the spin transition occurs at $250 \mathrm{~K}$ with a thermal hysteresis width of $80 \mathrm{~K}$. For the $m$-tos salt, the abrupt spin transition was observed at $319 \mathrm{~K}$, where hysteresis was negligible. The spin transition of the $p$-tos salt occurs abruptly at $295 \mathrm{~K}$ in the cooling process, while stepwise spin transitions were observed on heating. It should be noted that the $T_{1 / 2} \downarrow$ strongly depends on the structural-isomerized counter anions compared to $T_{1 / 2} \uparrow$. Such a remarkable structural isomerism effect should be related to the arrangement of counter anions among $\left[\mathrm{Fe}(\mathrm{II})\left(\mathrm{NH}_{2} \text {-trz }\right)_{3}\right]$ chains.

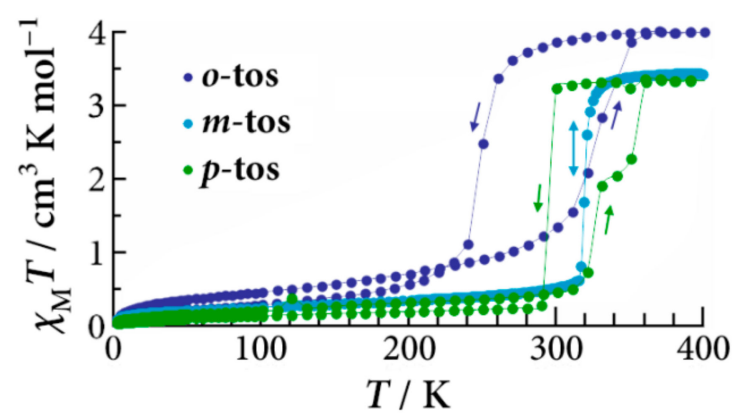

Figure 6. Temperature dependence of the magnetic susceptibility multiplied by temperature $\left(\chi_{\mathrm{M}} T\right)$ for $\left[\mathrm{Fe}(\mathrm{II})\left(\mathrm{NH}_{2}-\mathrm{trz}\right)_{3}\right](o-, m-\text {, and } p \text {-tos })_{2} \cdot x \mathrm{H}_{2} \mathrm{O}$. The arrows represent the sweeping directions of temperature. Reproduced with permission from Reference [24].

The SCO behavior of $\left[\mathrm{Fe}(\mathrm{III})\left(\mathrm{NH}_{2} \text {-trz }\right)_{3}\right](\text { tos })_{2} \cdot x \mathrm{H}_{2} \mathrm{O}$ was also confirmed by ${ }^{57} \mathrm{Fe}$ Mössbauer spectroscopy. Figure 7 shows the ${ }^{57} \mathrm{Fe}$ Mössbauer spectra of $\left[\mathrm{Fe}(\mathrm{II})\left(\mathrm{NH}_{2} \text {-trz }\right)_{3}\right](\operatorname{tos})_{2} \cdot x \mathrm{H}_{2} \mathrm{O}$ at 290 and $77 \mathrm{~K}$ [24]. For ${ }^{57} \mathrm{Fe}$ Mössbauer spectroscopy, the powder samples were dominant in the complexes. The LS state remained dominant upon heating to $290 \mathrm{~K}$, which is apparently different from those in the heating process. This is indicative of thermal hysteresis. For the $m$-tos salt, the ${ }^{57} \mathrm{Fe}$ Mössbauer spectra was almost unchanged below $290 \mathrm{~K}$, both in the cooling and heating processes, indicating a stable ground LS state. The ${ }^{57} \mathrm{Fe}$ Mössbauer study is consistent with the magnetic sealed in an acrylate resin sample holder to avoid the desorption of crystal water during the heating process. Two doublets were found in the ${ }^{57} \mathrm{Fe}$ Mössbauer spectra of the $o$ - and $p$-tos salts at $290 \mathrm{~K}$. The doublets with small and large quadrupole splitting are assigned to the LS and HS states, respectively. On cooling down to $77 \mathrm{~K}$, the HS signals considerably decreased, and the LS state became measurable. 


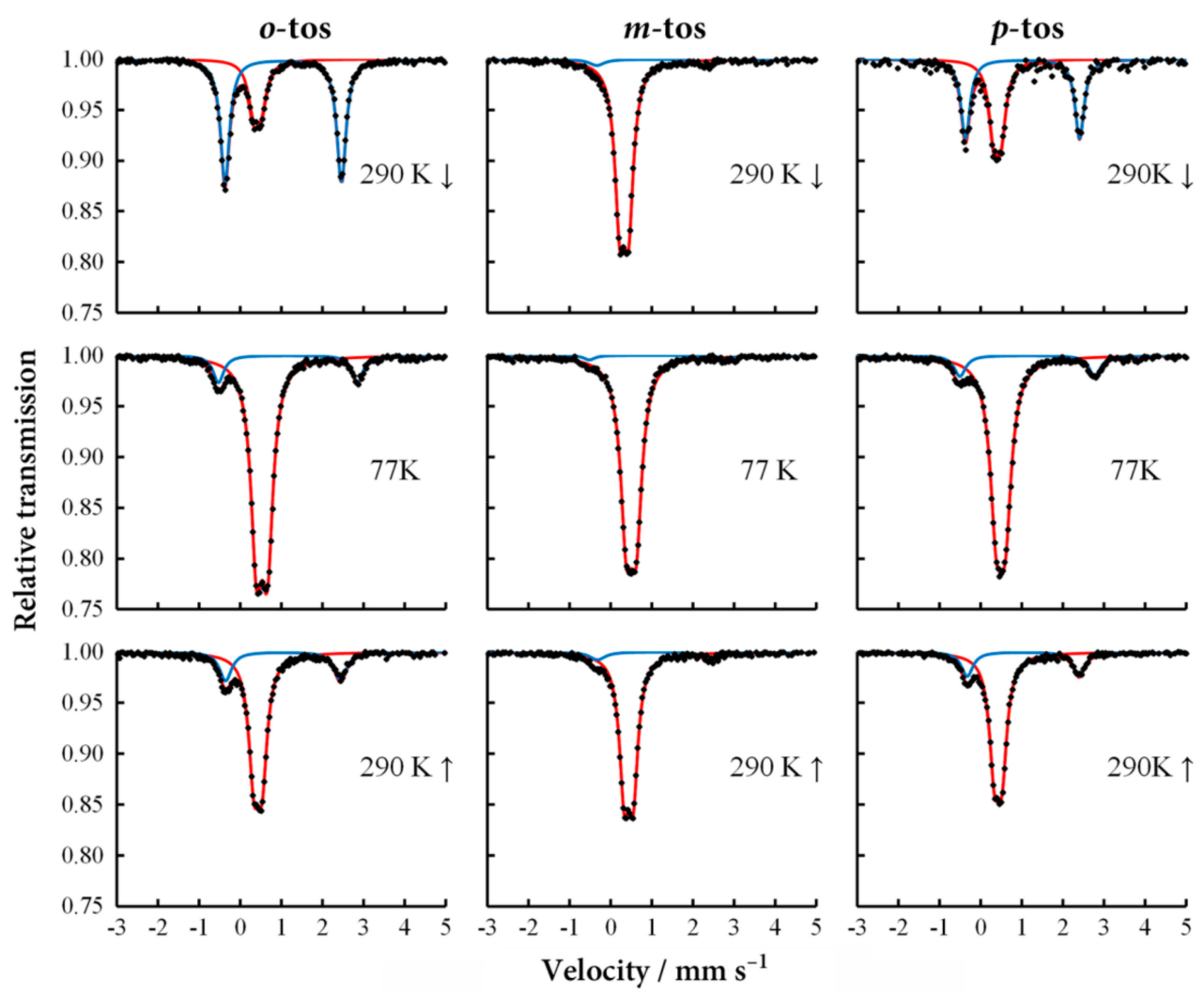

Figure 7. ${ }^{57} \mathrm{Fe}$ Mössbauer spectra for $\left[\mathrm{Fe}(\mathrm{II})\left(\mathrm{NH}_{2} \text {-trz }\right)_{3}\right](o-, m-, p \text {-tos })_{2} \cdot x \mathrm{H}_{2} \mathrm{O}$ at $290 \mathrm{~K}$ and $77 \mathrm{~K}$. Reproduced with permission from Reference [24].

Figure 8 shows the Fourier transform of Fe K-edge EXAFS oscillation function, $k^{3} \chi(k)$, for [Fe(II) $\left.\left(\mathrm{NH}_{2} \text {-trz) }\right)_{3}\right](\mathrm{abs})_{2} \cdot 2 \mathrm{H}_{2} \mathrm{O}$ at $30 \mathrm{~K}$ [25]. The dominant peaks at about $1.7 \AA$ are attributed to the $\mathrm{N}$ atoms of the $\mathrm{FeN}_{6}$ core with six-fold coordination. The first-nearest neighbor $\mathrm{Fe}-\mathrm{N}$ distances at $30 \mathrm{~K}$ were estimated at $1.974 \AA, 1.974 \AA$, and $1.978 \AA$, for the $o$-abs, $m$-abs, and $p$-abs salts, respectively, which is typical of Fe-N distances in the LS state. On the other hand, those at $350 \mathrm{~K}$ were estimated at $2.165 \AA, 2.158 \AA$, and $2.167 \AA$, for the $o$-abs, $m$-abs, and $p$-abs salts, respectively, which are typical of $\mathrm{Fe}-\mathrm{N}$ distances in the HS state. All the salts show a noticeable peak at about $7 \AA$, corresponding to the $\mathrm{Fe}-\mathrm{Fe}-\mathrm{Fe}$ multiple scattering, which proves the existence of a straight 1D Fe chain structure.

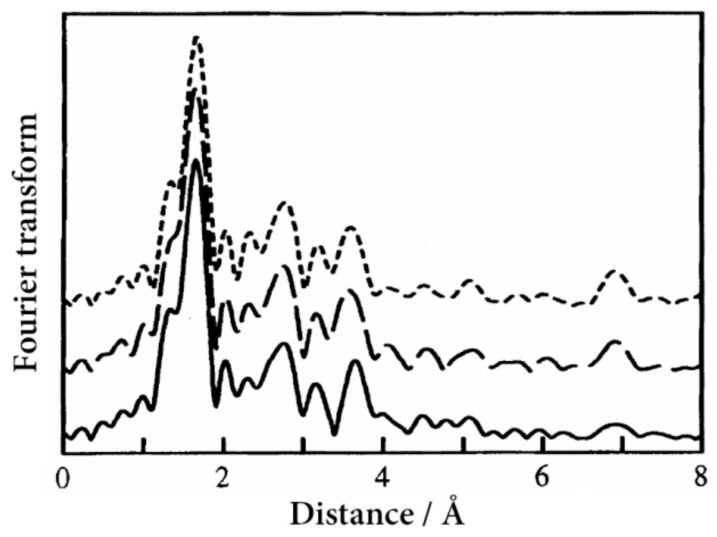

Figure 8. Fourier transform of Fe K-edge EXAFS oscillation function, $k^{3} \chi(k)$, for $\left[\mathrm{Fe}(\mathrm{II})\left(\mathrm{NH}_{2}-\mathrm{trz}\right)_{3}\right]\left(o^{-}\right.$, $m-, p$-abs $)_{2} \cdot 2 \mathrm{H}_{2} \mathrm{O}$ at $30 \mathrm{~K}$. The dotted line represents $o$-abs salt, the broken line denotes the $m$-abs salt, and the solid line represents the $p$-abs salt [25]. 
The temperature dependence of the magnetic susceptibility of $\left[\mathrm{Fe}(\mathrm{II})\left(\mathrm{NH}_{2} \text {-trz }\right)_{3}\right](\mathrm{abs})_{2} \cdot 2 \mathrm{H}_{2} \mathrm{O}$ is shown in Figure 9 [25]. In the first cycle of the heating process, the spin transition of the $o-, m-$, and $p$-abs salts occurred at $350 \mathrm{~K}, 320 \mathrm{~K}$, and 240 and $340 \mathrm{~K}$, respectively. These transition temperatures are typical of $\left[\mathrm{Fe}(\mathrm{II})\left(\mathrm{NH}_{2} \text {-trz }\right)_{3}\right]$ complexes showing $\mathrm{SCO}$ around or above room temperature. Unlike the case of the tos salts, the spin transitions of all the abs salts in the second cycle remain practically unchanged. This may be related to the fact that the abs molecules have both the amino (hydrogen bond donor) and sulfonate (hydrogen bond acceptor) groups which can form a tight hydrogen bond network with itself, while the tos molecules lack a hydrogen bond donor site.

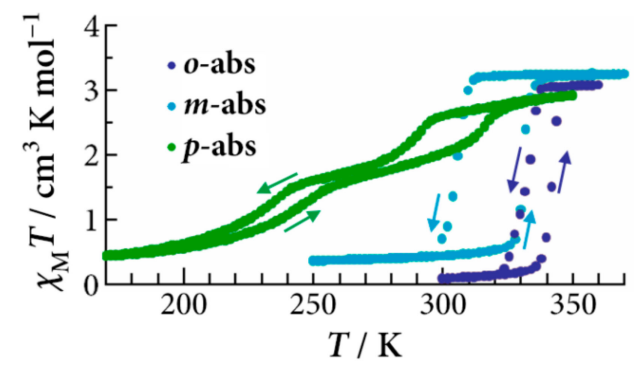

Figure 9. Temperature dependence of the magnetic susceptibility multiplied by temperature $\left(\chi_{\mathrm{M}} T\right)$ of $\left[\mathrm{Fe}(\mathrm{II})\left(\mathrm{NH}_{2} \text {-trz }\right)_{3}\right](\mathrm{abs})_{2} \cdot 2 \mathrm{H}_{2} \mathrm{O}$. The arrows represent the sweeping directions of temperature. Reproduced with permission from Reference [25].

In connection with the effect of structural isomerism of counter ions on the SCO behavior for the $\left[\mathrm{Fe}(\mathrm{II})(\mathrm{R} \text {-trz })_{3}\right]$ system, it should be mentioned that, as an example of using organic counter ions, Koningsbruggen et al. reported [Fe(II)( $\left.\left(\mathrm{NH}_{2} \text {-trz }\right)_{3}\right]$ complexes with naphthalenesulfonates and its derivatives [40], allowing for systematic variation of the anions. The sulfonate group can be placed in two different positions on the naphthalene ring where the anions have a potential to be modified with further functional groups, such as the hydroxyl and amino groups, forming hydrogen bonds. According to them, the $\mathrm{SCO}$ temperatures of $\left[\mathrm{Fe}(\mathrm{II})\left(\mathrm{NH}_{2}-\mathrm{trz}\right)_{3}\right] \mathrm{X}_{2} \cdot x \mathrm{H}_{2} \mathrm{O}$ (where $\mathrm{X}$ was 1-naphthalenesulfonate, 4-hydroxy-1-naphthalenesulfonate, 4-amino-1-naphthalenesulfonate, 2-naphthalenesulfonate, or 6-hydroxy-2-naphthalenesulfonate) were determined from the optical measurements. All the compounds show roughly the same SCO behavior, where the spin transition occurred irreversibly in the first heating process, before reproducible transitions with thermal hysteresis widths of about $10 \mathrm{~K}$, in the subsequent measuring cycles. In the first heating process, the complexes show an abrupt spin transition at 330 to $340 \mathrm{~K}$ accompanied by an apparent absorption change. A wide thermal hysteresis width of approximately $100 \mathrm{~K}$ was observed in the subsequent cooling process. However, the spin transition on the subsequent heating process occurred at much lower temperatures, ranging from 229 to $297 \mathrm{~K}$, depending on the anion. The reproducible hysteresis width was about $10 \mathrm{~K}$ for all the complexes.

As mentioned above, in the $\left[\mathrm{Fe}(\mathrm{II})\left(\mathrm{NH}_{2} \text {-trz }\right)_{3}\right] \mathrm{X}_{2} \cdot x \mathrm{H}_{2} \mathrm{O}$ system, $T_{1 / 2}$ and its hysteresis width vary drastically with the structural isomerism of counter ions, which implies the possibility of photoinduced spin transition by means of the photoisomerization of the counter ions. Based on this strategy, we synthesized [Fe(II)( $\mathrm{NH}_{2}$-trz $\left.)_{3}\right](\mathrm{SP} 150)_{2} \cdot 2 \mathrm{H}_{2} \mathrm{O}$ by using $\mathrm{SP} 150$ as a photochromic anion, and investigated the SCO behavior [26]. Figure 10 shows the molecular structure of SP150.

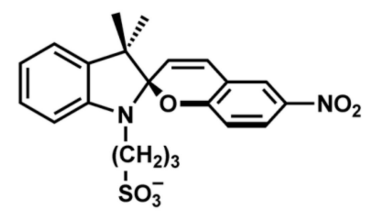

Figure 10. Molecular structure of a photochromic anion, SP150. 
To prove the formation of a 1D Fe chain structure, [Fe(II)(NH $\mathrm{NH}_{2}$-trz $\left.)_{3}\right]_{\infty}$, in $\left[\mathrm{Fe}(\mathrm{II})\left(\mathrm{NH}_{2}-\mathrm{trz}\right)_{3}\right]$ $(\mathrm{SP} 150)_{2} \cdot 2 \mathrm{H}_{2} \mathrm{O}$, we performed the Fe K-edge EXAFS spectra [26]. The Fourier transform at $30 \mathrm{~K}$ is shown in Figure 11. The peak at about $6.8 \AA$ corresponds to the Fe-Fe-Fe multiple scattering, which proves the formation of straight $1 \mathrm{D}$ Fe chain structure in $\left[\mathrm{Fe}(\mathrm{II})\left(\mathrm{NH}_{2}-\mathrm{trz}\right)_{3}\right](\mathrm{SP} 150)_{2} \cdot 2 \mathrm{H}_{2} \mathrm{O}$.

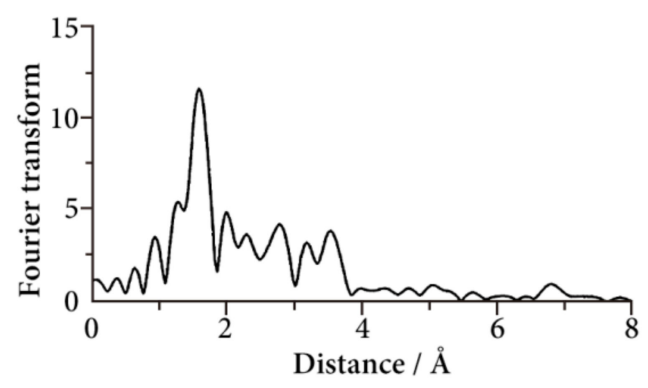

Figure 11. Fourier transform of Fe K-edge EXAFS oscillation function, $k^{3} \chi(k)$, for [Fe(II) $\left.\left(\mathrm{NH}_{2} \text {-trz }\right)_{3}\right]$ $(\mathrm{SP} 150)_{2} \cdot 2 \mathrm{H}_{2} \mathrm{O}$ at $30 \mathrm{~K}[26]$.

Figure 12 shows the temperature dependence of $\chi_{\mathrm{M}} T$ for $\left[\mathrm{Fe}(\mathrm{II})\left(\mathrm{NH}_{2} \text {-trz }\right)_{3}\right](\mathrm{SP} 150)_{2} \cdot 2 \mathrm{H}_{2} \mathrm{O}$. At first, $\chi_{\mathrm{M}} T$ was measured from $298 \mathrm{~K}$ to $10 \mathrm{~K}$. After cooling down to $10 \mathrm{~K}, \chi_{\mathrm{M}} T$ was measured from $10 \mathrm{~K}$ to $370 \mathrm{~K}$ during the heating process, where a partial and gradual SCO phenomenon appears at around $340 \mathrm{~K}$. After heating up to $370 \mathrm{~K}, \chi_{\mathrm{M}} T$ versus $T$ during the cooling process, from $370 \mathrm{~K}$ to $10 \mathrm{~K}$, shows a completely different line from that during the first heating process, and a gradual SCO appears at around $260 \mathrm{~K}$. The $\chi_{\mathrm{M}} T$ versus $T$ during the cooling process from $370 \mathrm{~K}$ to $10 \mathrm{~K}$ was reproduced on the third cycle. The irreversible SCO behavior is considered to be the rearrangement of crystal water molecules and/or SP150 molecules by annealing.

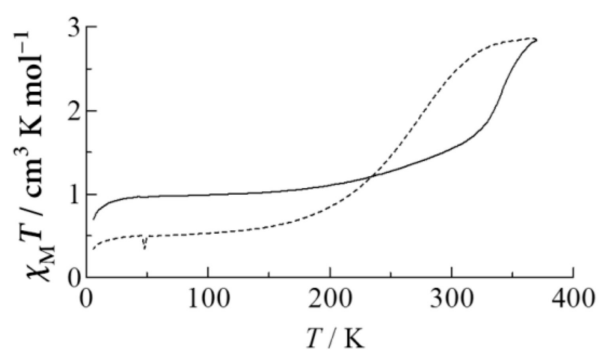

Figure 12. Temperature dependence of the magnetic susceptibility multiplied by temperature $\left(\chi_{\mathrm{M}} T\right)$ for [Fe(II) $\left(\mathrm{NH}_{2} \text {-trz) } 3 \text { ] (SP150) }\right)_{2} \cdot 2 \mathrm{H}_{2} \mathrm{O}$ [26]. The solid line denotes the process from $298 \mathrm{~K} \rightarrow 10 \mathrm{~K} \rightarrow 370 \mathrm{~K}$, and the dotted line represents the process from $370 \mathrm{~K} \rightarrow 10 \mathrm{~K} \rightarrow 298 \mathrm{~K}$.

\section{The Effect of Counter Ion Size on SCO for the [Fe(II)(R-trz) $\left.)_{3}\right]$ System}

The SCO characteristics are strongly influenced by counter ions in the triazole-bridged iron(II) systems as well as in a number of SCO materials. One of the importance instances of this is the counter ion dependence on the transition temperature and thermal hysteresis in a $\left[\mathrm{Fe}(\mathrm{II})\left(\mathrm{NH}_{2} \text {-trz }\right)_{3}\right]$-type system with monovalent inorganic anions, such as $\mathrm{Cl}^{-}, \mathrm{Br}^{-}, \mathrm{NO}_{3}{ }^{-}, \mathrm{I}^{-}, \mathrm{BF}_{4}{ }^{-}$, and $\mathrm{ClO}_{4}{ }^{-}$. An example where the ion radius directly influences the transition temperature is the $\mathrm{SCO}$ phenomena of [Fe(II) $\left.\left(\mathrm{NH}_{2} \text {-trz }\right)_{3}\right] \mathrm{X}_{2}\left(\mathrm{X}=\mathrm{Cl}^{-}, \mathrm{Br}^{-}, \mathrm{NO}_{3}{ }^{-}, \mathrm{I}^{-}, \mathrm{BF}_{4}^{-}, \mathrm{ClO}_{4}^{-}\right)$[37-39]. The transition temperature and hysteresis width linearly decreased from 355 to $180 \mathrm{~K}$ depending on the ionic radii of the spherical anions, denoted by the filled triangles in Figure 13. A similar tendency was discovered in other triazole-based SCO complexes. Garcia et al. reported this in $\left[\mathrm{Fe}(\mathrm{II})\left(\right.\right.$ hye-trz) $\left.{ }_{3}\right] \mathrm{X}_{2} \cdot x \mathrm{H}_{2} \mathrm{O}$ (hye-trz $=$ 4-(2'-hydroxyethyl)-1,2,4-triazole, $\mathrm{X}=\mathrm{PF}_{6}{ }^{-}, \mathrm{ClO}_{4}{ }^{-}, \mathrm{BF}_{4}^{-}, \mathrm{I}^{-}, \mathrm{Br}^{-}, \mathrm{NO}_{3}{ }^{-}$, and $\left.\mathrm{Cl}^{-}\right)$[41]. The transition temperatures, determined by optical measurement, linearly decrease in correlation with ionic radii from 314 to $205 \mathrm{~K}$, represented by the open triangles in Figure 13. 


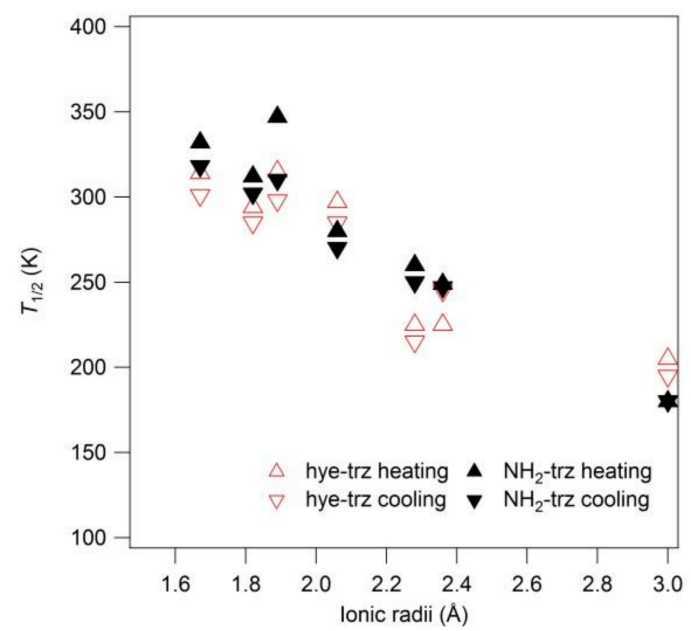

Figure 13. Variation of the transition temperatures versus the ionic radii for $\left[\mathrm{Fe}(\mathrm{II})\left(\mathrm{NH}_{2}-\mathrm{trz}\right)_{3}\right] \mathrm{X}_{2} \cdot x \mathrm{H}_{2} \mathrm{O}$ and $\left[\mathrm{Fe}(\mathrm{II})(\text { hye-trz) })_{3}\right] \mathrm{X}_{2} \cdot x \mathrm{H}_{2} \mathrm{O}[37-39,41]$.

Among the same series of anions, the Fe-N coordination bond length will likely decrease according to the enhancement of the anion-cation interactions, which have been investigated using EXAFS techniques in combination with ${ }^{57} \mathrm{Fe}$ Mössbauer [42] and X-ray fluorescence spectroscopy [38]. The anion-cation interaction can be regarded as a kind of chemical pressure, which originates in intermolecular interactions and would provide an effect similar to physical hydrostatic pressure on SCO phenomena, except for the changes in chemical properties.

Moreover, Garcia et al. reported on the correlation between $T_{1 / 2}$ and the volume of the counter anion in the series of fluorinated inorganic divalent anions $\left(\mathrm{TiF}_{6}{ }^{2-}, \mathrm{ZrF}_{6}{ }^{2-}, \mathrm{SnF}_{6}{ }^{2-}, \mathrm{GeF}_{6}{ }^{2-}\right.$, and $\left.\mathrm{TaF}_{7}{ }^{2-}\right)$ salts of [Fe(II) $\left(\mathrm{NH}_{2} \text {-trz }\right)_{3}$ ] complexes, in addition to the related monovalent complexes [43]. These divalent anions are expected to favor the engineering of hydrogen-bonding networks. They considered the variation of $T_{1 / 2}$ with the volume of the counter anion, instead of considering only the radius determined from Kapustinskii's equation [44]. This allows us to take into account the dimensional volume $(V)$ of the anions. Two linear regimes were found in the regions of $0.04 \mathrm{~nm}^{3}$ $\leq V \leq 0.09 \mathrm{~nm}^{3}$ and $V \geq 0.11 \mathrm{~nm}^{3}$. In the former, corresponding with the monovalent anions, $T_{1 / 2}$ decreases linearly with increasing volume, and spin transition requires less energy. Above a $V$ of 0.11 $\mathrm{nm}^{3}$, corresponding with the divalent anions, it seems that $T_{1 / 2}$ is almost constant at about $200 \mathrm{~K}$. These complexes seem to have enough chain distance to freely expand the $\mathrm{Fe}-\mathrm{N}$ coordination bonds, so that the counter anions hardly affect the spin transition. Thus, a larger counter anion induces the reduction of the relative energy of the potential wells between the HS and LS states, resulting in a negative pressure effect. Indeed, $\left[\mathrm{Fe}(\mathrm{II})\left(\mathrm{NH}_{2} \text {-trz }\right)_{3}\right]\left(\mathrm{B}_{10} \mathrm{H}_{10}\right) \cdot \mathrm{H}_{2} \mathrm{O}$ shows the HS state over the temperature range of 300 to $2 \mathrm{~K}$, which contains the largest counter anion in reported systems, with $V$ being approximately $0.23 \mathrm{~nm}^{3}$ [45].

\section{Fastener Effect of Counter Ions on SCO for the [Fe(II)(R-trz) $\left.)_{3}\right]$ System}

As described in Section 4, $T_{1 / 2}$ increases with decreasing the ionic radii of counter anions in $\left[\mathrm{Fe}(\mathrm{II})\left(\mathrm{NH}_{2} \text {-trz }\right)_{3}\right] \mathrm{X}_{2} \cdot x \mathrm{H}_{2} \mathrm{O}$. The charge density of the anion increases with decreasing the ionic radius, leading to incremental anion-cation interaction between the $\left[\mathrm{Fe}(\mathrm{II})\left(\mathrm{NH}_{2}-\mathrm{trz}\right)_{3}\right]$ unit, the anion, and the compression of the $\mathrm{FeN}_{6}$ coordination sphere, which induces two effects: the incremental intrachain (short-range) interaction and ligand field strength. Furthermore, $T_{1 / 2}$ increases due to both of these effects. We also observed an effect on uniaxial chemical pressure along the direction of the [Fe(II) $\left.\left(\mathrm{NH}_{2} \text {-trz }\right)_{3}\right]_{\infty}$ chain by van der Waals force between alkanesulfonate anions $\left(\mathrm{C}_{n} \mathrm{H}_{2 n+1} \mathrm{SO}_{3}{ }^{-}\right.$, $n=1-9)$ in the series of $\left[\mathrm{Fe}(\mathrm{II})\left(\mathrm{NH}_{2}-\mathrm{trz}\right)_{3}\right]\left(\mathrm{C}_{n} \mathrm{H}_{2 n+1} \mathrm{SO}_{3}\right)_{2} \cdot x \mathrm{H}_{2} \mathrm{O}$. Magnetostructural correlation between $T_{1 / 2}$ and the Fe-Fe distance is described in this section. 
To determine the local structure around Fe ions for these complexes, Fe K-edge EXAFS measurements were conducted. This measurement is a useful tool to reveal the local structure around iron(II) ions in $\left[\mathrm{Fe}(\mathrm{III})(\mathrm{R}-\operatorname{trz})_{3}\right]$ Anion $\cdot x \mathrm{H}_{2} \mathrm{O}$; however, the crystal structure has become clearer in recent studies [12,46,47].

The Fourier-transformed Fe K-edge EXAFS spectra at $35 \mathrm{~K}$ (LS state) and $370 \mathrm{~K}$ (HS state) are shown in Figure 14. The most intense peak around $1.7 \AA$ is attributed to the $\mathrm{N}$ atoms in the six-fold $\mathrm{FeN}_{6}$ coordination environment. The peak obviously moved to the longer side according to the change from the HS to LS state. Multiple peaks were found in the range of 2-4 $\AA$, which were attributed to the $\mathrm{Fe}-\mathrm{N}, \mathrm{Fe}-\mathrm{C}$, and $\mathrm{Fe}-\mathrm{Fe}$ coordination shells and multiple-scattering paths. For the methanesulfonate compound ( $n=1)$, the closest Fe-N distance of the LS state is estimated to be 1.977 to $1.984 \AA$ at $35 \mathrm{~K}$. For the other compounds ( $n=2$ to 9), the Fe-N distances were estimated to be 1.965 to $1.983 \AA$ (LS state), which are close to that of the methanesulfonate compound. Accordingly, the Fe-N distances are insensitive to the chain length of alkanesulfonates. As shown in Figure 15, we found that the estimated Fe-Fe distances decreased from 3.34 to $3.29 \AA$ accompanied by the even-odd effect with increasing alkyl chain length. This tendency is caused by the fastener effect that was derived from van der Waals interactions between self-assembled alkyl chains. It is worth noting that we can apply uniaxial pressure to the triazole-bridged Fe(II) system along the 1D chain direction by causing the fastener effect. Figure 16 shows a schematic illustration of the compression of the [Fe(II) $\left.\left(\mathrm{NH}_{2} \text {-trz }\right)_{3}\right]$ chain associated with the fastener effect. The Fe chain can be assumed to follow the self-assembling interaction between alkyl chains, where the Fe chain would be compressed along the direction of $\mathrm{Fe}-\mathrm{Fe}$ array with increasing the fastener effect. At this time, the linear arrangement of iron atoms could likely be maintained with compensatory in $\mathrm{N}-\mathrm{Fe}-\mathrm{N}$ bridging angle. This concept is supported by the Fe-Fe-Fe multiple scattering peaks around $7 \AA$ in EXAFS spectra (Figure 14a) [27]. [Fe(II) $\left.\left(\mathrm{NH}_{2} \text {-trz }\right)_{3}\right]\left(\mathrm{C}_{n} \mathrm{H}_{2 n+1} \mathrm{SO}_{3}\right)_{2} \cdot x \mathrm{H}_{2} \mathrm{O}$ is a unique system which has a varying $\mathrm{Fe}-\mathrm{Fe}$ interaction.

(a)

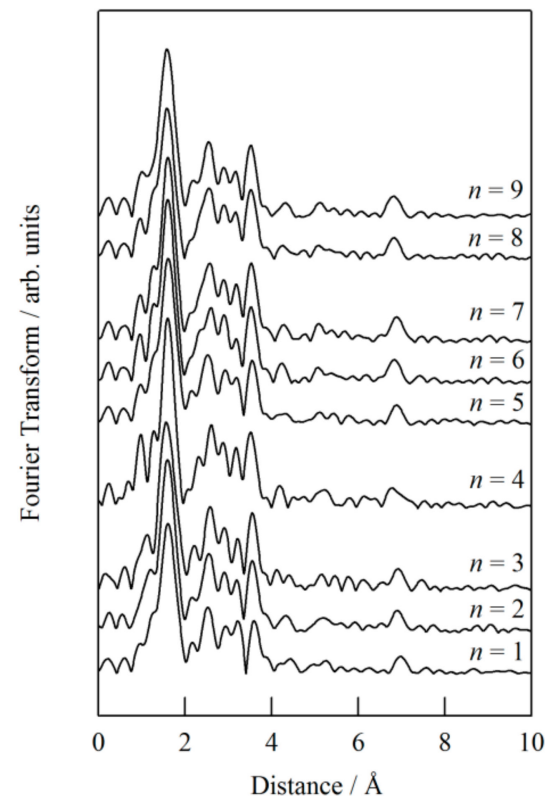

(b)

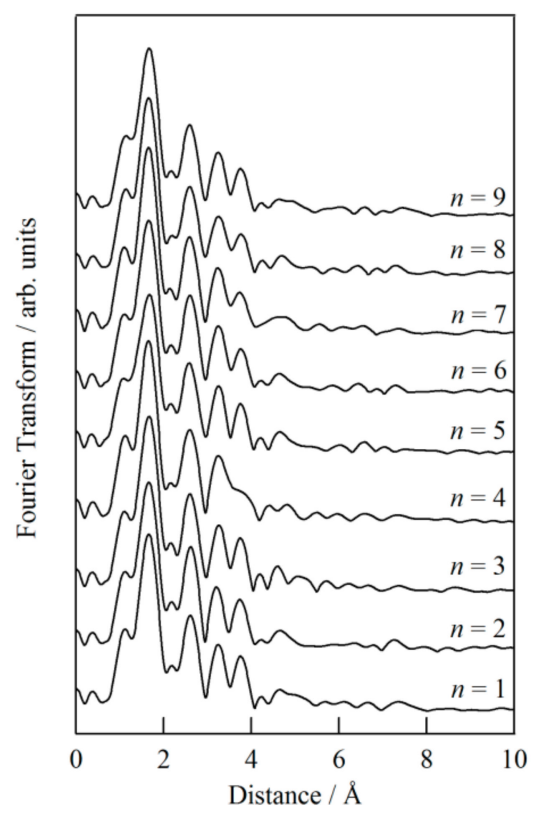

Figure 14. Fourier transform of Fe K-edge EXAFS oscillation functions, $k^{3} \chi(k)$, for [Fe(II)( $\mathrm{NH}_{2}$-trz $)_{3}$ ] $\left(\mathrm{C}_{n} \mathrm{H}_{2 n+1} \mathrm{SO}_{3}\right)_{2} \cdot x \mathrm{H}_{2} \mathrm{O}(n=1-9)$ at (a) $35 \mathrm{~K}$, low-spin (LS) state; and (b) $370 \mathrm{~K}$, high-spin (HS) state [27]. 
(a)

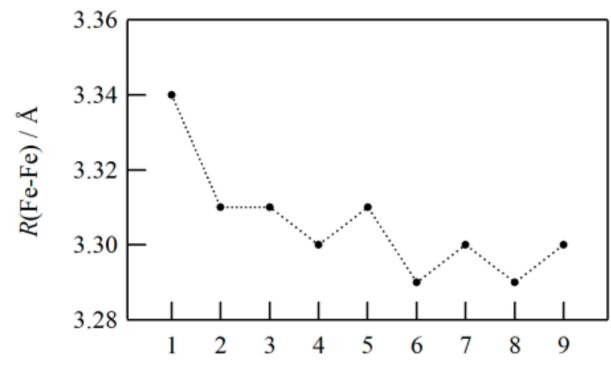

(b)

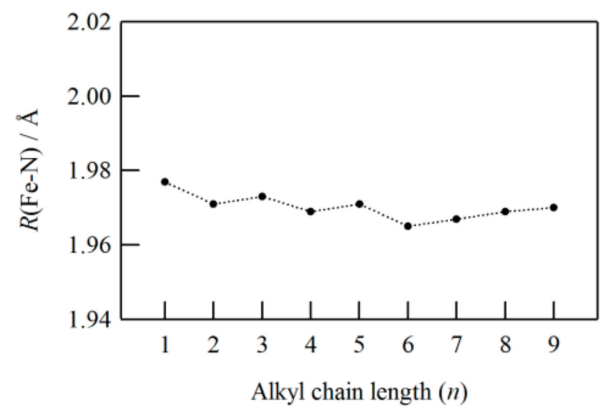

Figure 15. The nearest-neighbor (a) $\mathrm{Fe}-\mathrm{Fe}$ and (b) $\mathrm{Fe}-\mathrm{N}$ distances as a function of the alkyl chain length (n) at $35 \mathrm{~K}$ for $\left[\mathrm{Fe}(\mathrm{II})\left(\mathrm{NH}_{2}-\mathrm{trz}\right)_{3}\right]\left(\mathrm{C}_{n} \mathrm{H}_{2 n+1} \mathrm{SO}_{3}\right)_{2} \cdot x \mathrm{H}_{2} \mathrm{O}(n=1-9)$ [27].

(a)

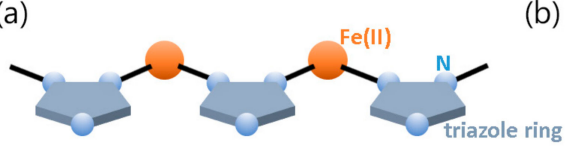

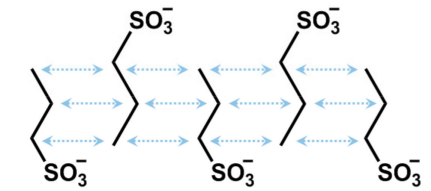

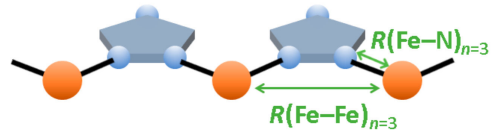

(b)
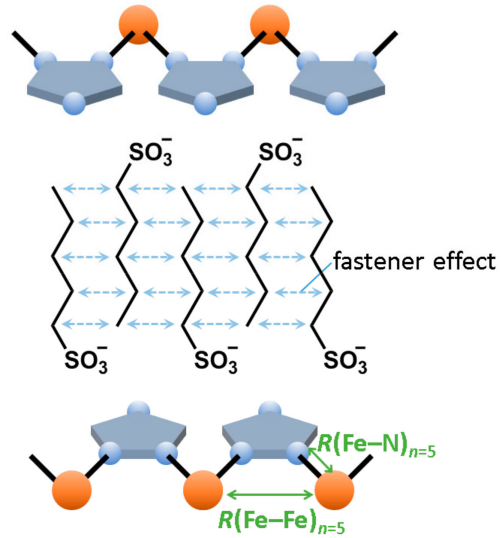

Figure 16. Schematic representation of the fastener effect on $R(\mathrm{Fe}-\mathrm{Fe})$ and $R(\mathrm{Fe}-\mathrm{N})$ for $\left[\mathrm{Fe}(\mathrm{II})\left(\mathrm{NH}_{2}-\mathrm{trz}\right)_{3}\right]\left(\mathrm{C}_{n} \mathrm{H}_{2 n+1} \mathrm{SO}_{3}\right)_{2} \cdot x \mathrm{H}_{2} \mathrm{O} ;(\mathbf{a}) n=3$ and $(\mathbf{b}) n=5$.

Figure 17 shows the temperature dependence of $\chi_{\mathrm{M}} T$ in the temperature range of 250 to $370 \mathrm{~K}$. In the case of $n=1$, the $\chi_{\mathrm{M}} T$ value observed at $320 \mathrm{~K}$ was $3.42 \mathrm{~cm}^{3} \cdot \mathrm{K} \cdot \mathrm{mol}^{-1}$ and is quite close to the theoretical value for the HS state $(S=2)$. On cooling, the value started to decrease abruptly around $280 \mathrm{~K}\left(T_{1 / 2} \downarrow=276 \mathrm{~K}\right)$ and then arrived a value of $0.21 \mathrm{~cm}^{3} \cdot \mathrm{K} \cdot \mathrm{mol}^{-1}$. In the subsequent heating process, the spin transition occurred at $T_{1 / 2} \uparrow$ of $295 \mathrm{~K}$ and the $\chi_{\mathrm{M}} T$ value was restored completely. The thermal hysteresis width $\left(\Delta T_{1 / 2}=T_{1 / 2} \uparrow-T_{1 / 2} \downarrow\right)$ is $19 \mathrm{~K}$.

As can be seen in Figure 18a, $T_{1 / 2}$ increases as the number of carbons in the alkyl chain increase up to $n=4$ accompanied by the even-odd effect. However, it remains almost constant above $n=5$. In connection with this, $T_{1 / 2}$ has relevant, significant impacts on the nearest-neighbor Fe-Fe distances $(R(\mathrm{Fe}-\mathrm{Fe}))$, estimated from EXAFS to be $35 \mathrm{~K}$. Taking into account that the alkyl chain length has negligible influence on $R(\mathrm{Fe}-\mathrm{N}), T_{1 / 2}$ is considered to be mainly related to $R(\mathrm{Fe}-\mathrm{Fe})$. The displacement of iron(II) ions in a 1D arrangement move coherently with counter anions due to the fastener effect, leading to the squeeze of the neighboring Fe-Fe distances. Consequently, the elastic energy of $\left[\mathrm{Fe}(\mathrm{II})\left(\mathrm{NH}_{2} \text {-trz }\right)_{3}\right]_{\infty}$ chains is considered to be increased. This situation is analogous to SCO behavior 
under external hydrostatic pressure [48-50], except that hydrostatic pressure is isotropic. Increasing external pressure provides narrow magnetic hysteresis width and a high $T_{1 / 2}$ value. For the $1 \mathrm{D}$ systems, SCO behavior affected by external pressure has been successfully described by using a model that takes into account the competing short- and long-range interactions, where the former represents the interaction of molecules inside the chain and the latter is assumed to arise from the coupling of the iron(II) d electrons with the deformation accompanied by the HS to LS transitions. When the short-range interaction overcomes the long-range one, the LS state becomes stable and leads the hysteresis loop to disappear [51]. This concept can be also applied to the present results. Increasing the alkyl chain length corresponds to the enhancement of the short-range interaction in the system. In fact, we found a close correlation between the $T_{1 / 2}$ value and the $R(\mathrm{Fe}-\mathrm{Fe})$ estimated from EXAFS as shown in Figure 18a, where $R(\mathrm{Fe}-\mathrm{Fe})$ is directly connected to the short-range interaction. In the range of $n \geq 5$, the fastener effect seems to reach a critical limit in shortening the Fe-Fe distance. To our knowledge, this is the first system with systematic control of the Fe-Fe interaction in the 1D triazole-coordinated iron(II) SCO complexes. Moreover, there is a noticeable difference between this and other studies that investigated the dependence of SCO behavior by spherical counter anions, as described in numerous previous reports and our compounds [24,25,37-39,41-43,45,52-56].
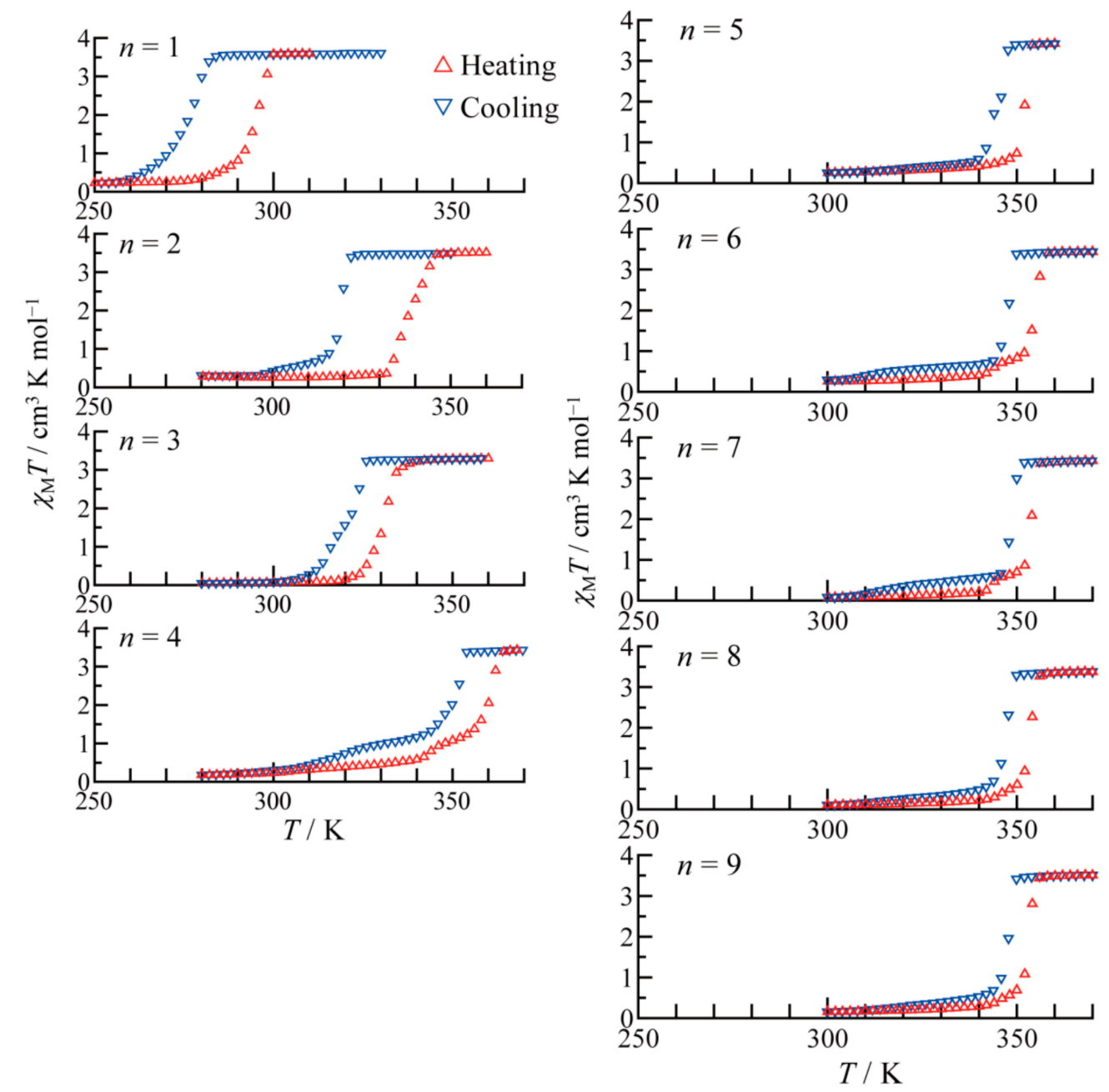

Figure 17. Temperature dependence of molar magnetic susceptibility multiplied by temperature for [Fe(II) $\left.\left(\mathrm{NH}_{2} \text {-trz }\right)_{3}\right]\left(\mathrm{C}_{n} \mathrm{H}_{2 n+1} \mathrm{SO}_{3}\right)_{2} \cdot x \mathrm{H}_{2} \mathrm{O}(n=1-9)$. Blue and red triangles represent the first cooling and the subsequent heating processes, respectively [27]. 
(a)

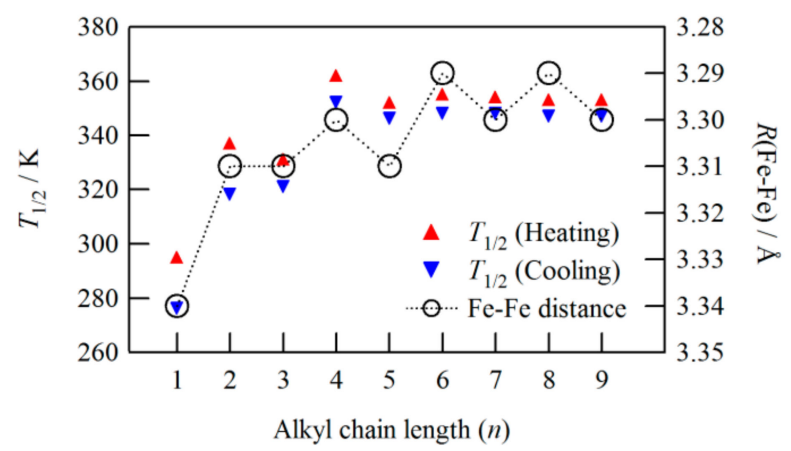

(b)

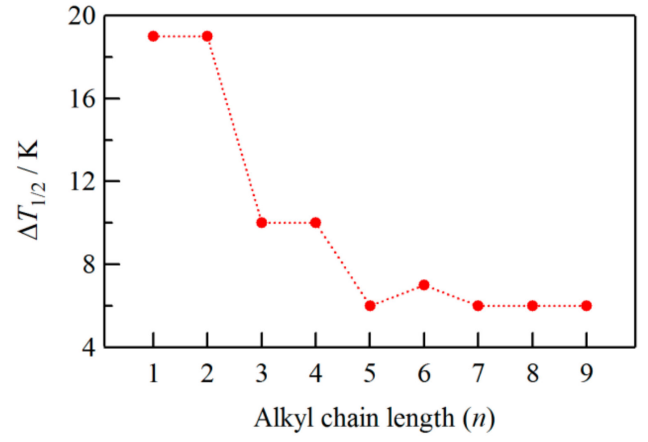

Figure 18. (a) Correlation between $T_{1 / 2}$ and $\mathrm{Fe}-\mathrm{Fe}$ distance at $35 \mathrm{~K}$ for $\left[\mathrm{Fe}(\mathrm{II})\left(\mathrm{NH}_{2} \text {-trz }\right)_{3}\right.$ ] $\left(\mathrm{C}_{n} \mathrm{H}_{2 n+1} \mathrm{SO}_{3}\right)_{2} \cdot x \mathrm{H}_{2} \mathrm{O}(n=1-9)$; and (b) hysteresis width of spin-crossover (SCO) transition $\left(\Delta T_{1 / 2}\right)$ as a function of alkyl chain length $(n)$ for $\left[\mathrm{Fe}(\mathrm{II})\left(\mathrm{NH}_{2} \text {-trz }\right)_{3}\right]\left(\mathrm{C}_{n} \mathrm{H}_{2 n+1} \mathrm{SO}_{3}\right)_{2} \cdot x \mathrm{H}_{2} \mathrm{O}(n=1-9)$ [27].

The relationship between $\Delta T_{1 / 2}$ and the alkyl chain length is shown in Figure 18b. A clear even-odd effect was also observed in the hysteresis width, where $\Delta T_{1 / 2}$ was slightly wider for even $n$ than for odd $n$. The magnitude of $\Delta T_{1 / 2}$ became smaller with increasing $n$ and saturated over $n=5$ at $\Delta T_{1 / 2} \sim 6 \mathrm{~K}$. This tendency, except for the even-odd effect, is the same as with [Fe(II)( $\mathrm{NH}_{2}$-trz $\left.)_{3}\right]$ with spherical counter anions. The counter anions are accommodated among the cationic iron(II) chains and behave as spacers. Accordingly, the incremental increase of anion size leads to detachment from the adjacent cationic SCO chains, and thereby interchain interaction, i.e., the cooperative effect, would decrease.

\section{Photoinduced SCO for the [Fe(II)(R-trz) $\left.)_{3}\right]$ System}

Since the first LIESST phenomenon was discovered with the SCO complex $\left[\mathrm{Fe}(\mathrm{II})(\mathrm{ptz})_{6}\right]\left(\mathrm{BF}_{4}\right)_{2}$ in 1984 [3], varied iron(II) and iron(III) compounds showing LIESST have been developed [5]. Being able to switch between non-magnetic and magnetically ordered states by light irradiation at room temperature will open a new field of photonic molecular devices. However, there still remains a limitation on the critical temperature in LIESST. The highest critical temperature is $130 \mathrm{~K}$ for $\left[\mathrm{Fe}(\mathrm{II})(\mathrm{L})(\mathrm{CN})_{2}\right] \cdot \mathrm{H}_{2} \mathrm{O}$ ( $\mathrm{L}$ is the Schiff base macrocyclic ligand derived from the condensation of 2,6-diacetylpyridine with 3,6-dioxaoctane-1,8-diamine) [57]. Therefore, another approach has been eagerly anticipated. Recently, the photoinduced SCO phenomenon has been demonstrated for $\left[\mathrm{Fe}(\mathrm{II})(\mathrm{pz})\left\{\mathrm{Pt}(\mathrm{CN})_{4}\right\}\right]$ (pz is pyrazine) [58] and [Fe(II) $\left.\left(\mathrm{NH}_{2}-\mathrm{trz}\right)_{3}\right](\mathrm{Br})_{2} \cdot 3 \mathrm{H}_{2} \mathrm{O}$ by photoirradiation within the thermal hysteresis loop of the SCO transition [59]. Such a strategy is one of the possible approaches to control the spin states in SCO compounds at room temperature.

In the $\left[\mathrm{Fe}(\mathrm{II})(\mathrm{pz})\left\{\mathrm{Pt}(\mathrm{CN})_{4}\right\}\right]$ complex, where thermal SCO transitions occur at $T \mathrm{c} \uparrow=284 \mathrm{~K}$ and $T \mathrm{c} \downarrow=308 \mathrm{~K}$ with a hysteresis width of $24 \mathrm{~K}$, light-induced spin transition at room temperature was achieved by applying one-shot laser-pulsed irradiation [58]. The photoinduced spin conversion was confirmed by investigating Raman bands at 650 and $682 \mathrm{~cm}^{-1}$ assigned to the in-plane bending mode of the pyrazine ring for the HS and LS states, respectively. Note that the photoinduced spin transition is reversible in the reported system. [ $\left.\mathrm{Fe}(\mathrm{II})\left(\mathrm{NH}_{2}-\operatorname{trz}\right)_{3}\right] \mathrm{Br}_{2} \cdot 3 \mathrm{H}_{2} \mathrm{O},\left[\mathrm{Fe}(\mathrm{II})\left(\mathrm{NH}_{2} \text {-trz }\right)_{3}\right]\left(\mathrm{NO}_{3}\right)_{2} \cdot \mathrm{H}_{2} \mathrm{O}$, 
and [Fe(II)(H-trz $\left.)_{2}(\operatorname{trz})\right]\left(\mathrm{BF}_{4}\right)_{2} \cdot \mathrm{H}_{2} \mathrm{O}$ are the second systems for the photoinduced LS to HS conversion in the thermal hysteresis region by a single shot of laser irradiation [60].

As for the triazole-bridged iron(II) SCO system, the development of single crystal or transparent film has been desired for the detailed investigation of the optical properties and the LIESST effect at low temperatures. However, the single crystal of triazole-bridged polymeric iron(II) complex has rarely been obtained, except for in a few complexes [12]. The triazole-bridged iron(II) chain system accepts various kinds of counter anions and exhibits a wide variety of spin transitions. From this viewpoint, we have developed $\left[\mathrm{Fe}(\mathrm{II})(\mathrm{R} \text {-trz })_{3}\right]$ films exhibiting the SCO phenomenon around room temperature and observed the LIESST effect below $30 \mathrm{~K}$, in which Nafion behaves as a counter anion as well as a transparent substrate [21,29].

To confirm the 1D chain structure in Nafion 117 film, the Fe K-edge EXAFS measurements were performed [21]. As shown in Figure 19, the dominant peak of the Fourier transform was observed around $1.7 \AA$ at $65 \mathrm{~K}$, corresponding to the Fe-N scattering. Furthermore, a noticeable peak can be found at $7 \AA$, indicating the formation of a 1D chain structure consisting of a linear Fe arrangement, as schematically shown in Figure 20.

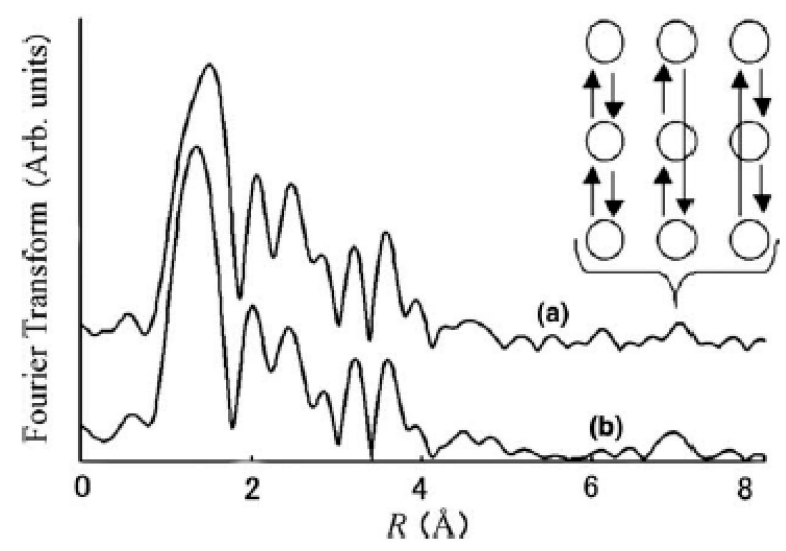

Figure 19. Fourier transforms of the Fe K-edge EXAFS oscillation function, $k^{3} \chi(k)$, for (a) [Fe(II)(H-trz) 3 ] @Nafion and (b) $\left[\mathrm{Fe}(\mathrm{II})\left(\mathrm{NH}_{2} \text {-trz }\right)_{3}\right] @$ Nafion at $65 \mathrm{~K}$ [21]. The inset shows the schematic representation of double-scattering $(1,2)$ and triple-scattering (3) from the next nearest neighbor Fe-Fe-Fe shell, which is responsible for the EXAFS peak at around $7 \AA$.

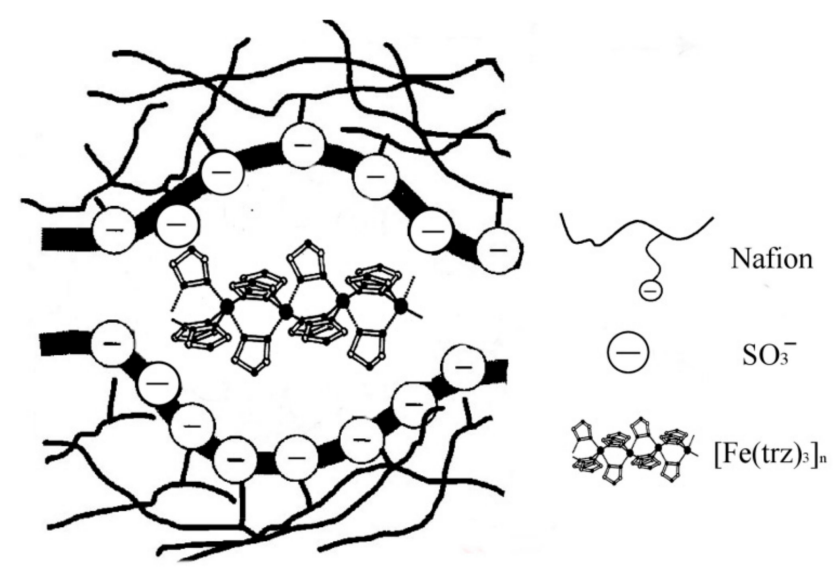

Figure 20. Schematic representation of the oligomer of $\left[\mathrm{Fe}(\mathrm{R}-\mathrm{trz})_{3}\right]_{n}{ }^{2 n+}$ embedded in Nafion 117.

The magnetic properties of $\left[\mathrm{Fe}(\mathrm{II})(\mathrm{H}-\mathrm{trz})_{3}\right] @ \mathrm{Nafion}$ and $\left[\mathrm{Fe}(\mathrm{II})\left(\mathrm{NH}_{2} \text {-trz) }\right)_{3}\right] \mathrm{Nafion}$ were measured at $0.1 \mathrm{~T}$ for the samples sealed in an aluminum capsule to prevent water loss [21]. Figure 21 shows the temperature dependence of $\chi T$ for both materials. For $\left[\mathrm{Fe}(\mathrm{II})(\mathrm{H}-\mathrm{trz})_{3}\right] @ \mathrm{Nafion}$, the reversible spin 
transition occurred around a $T_{1 / 2}$ of $260 \mathrm{~K}$, accompanied with a small thermal hysteresis width of $3 \mathrm{~K}$. The SCO transition for $\left[\mathrm{Fe}(\mathrm{II})\left(\mathrm{NH}_{2} \text {-trz }\right)_{3}\right] @$ Nafion was observed around a $T_{1 / 2}$ of $198 \mathrm{~K}$ without thermal hysteresis. Therefore, it seems that the hysteresis width $\left(\Delta T_{1 / 2}=3 \mathrm{~K}\right)$ of the spin transition for $\left[\mathrm{Fe}(\mathrm{II})(\mathrm{H}-\mathrm{trz})_{3}\right] @$ Nafion is attributed to the cooperative effect due to the intrachain interaction in $\left[\mathrm{Fe}(\mathrm{II})(\mathrm{H}-\mathrm{trz})_{3}\right]_{n}$.

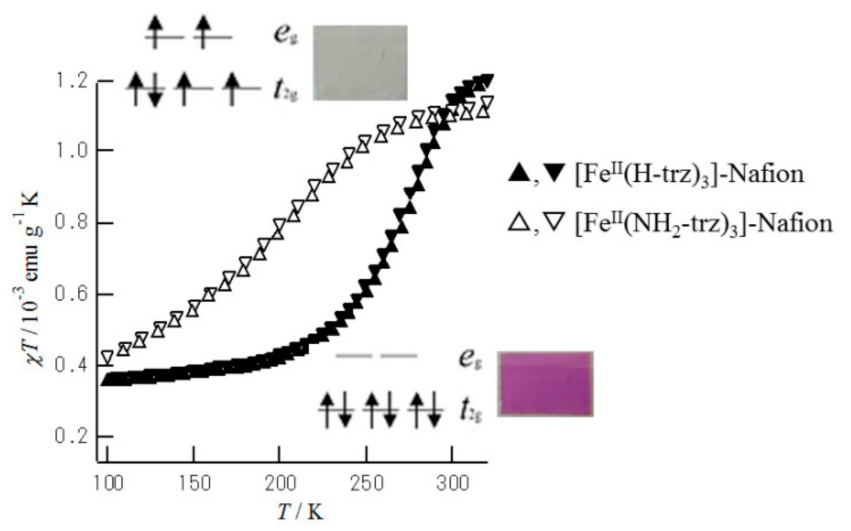

Figure 21. Temperature dependence of the magnetic susceptibility multiplied by temperature $(\chi T)$ for $\left[\mathrm{Fe}(\mathrm{II})(\mathrm{H}-\mathrm{trz})_{3}\right] @ \mathrm{Nafion}$ and $\left[\mathrm{Fe}(\mathrm{II})\left(\mathrm{NH}_{2} \text {-trz }\right)_{3}\right] @$ Nafion [21]. Upright and inverted triangles represent the heating and cooling processes, respectively. The inset demonstrates the thermochromism due to the SCO phenomenon for [Fe(II)(H-trz) $)_{3}$ @Nafion 117. Purple film in the LS state $\left(t_{2 \mathrm{~g}}{ }^{6}: S=0\right)$ at $77 \mathrm{~K}$; Colorless film in the HS state $\left(t_{2 \mathrm{~g}}{ }^{4} e_{\mathrm{g}}{ }^{2}: S=2\right)$ at $300 \mathrm{~K}$.

Figure 21 also indicates residual paramagnetic fraction below $200 \mathrm{~K}$, which is attributed to the HS state of iron(II). The residual HS fraction of iron(II) is attributed to the terminal iron(II) site in the oligomer of $\left[\mathrm{Fe}(\mathrm{II})(\mathrm{H}-\mathrm{trz})_{3}\right]_{n}{ }^{2 n+}$ in Nafion 117. It should be mentioned that in the iron(II) trimer complex, $\left[\mathrm{Fe}(\mathrm{II})_{3}(\mathrm{Et}-\mathrm{trz})_{6}\left(\mathrm{H}_{2} \mathrm{O}\right)_{6}\right]\left(\mathrm{CF}_{3} \mathrm{SO}_{3}\right)_{6}$, the central iron(II) site undergoes the LS-HS transition at about $200 \mathrm{~K}$, while the spin state of the terminal iron(II) sites is the HS state between $2 \mathrm{~K}$ and $300 \mathrm{~K}$ [61].

As shown in Figure 21, we demonstrated the thermochromism induced by the LS-HS transition for $\left[\mathrm{Fe}(\mathrm{II})(\mathrm{H}-\mathrm{trz})_{3}\right] @$ Nafion. The colors of the HS state $\left(t_{2 \mathrm{~g}}{ }^{4} e_{\mathrm{g}}{ }^{2}, S=2\right)$ and the LS state $\left(t_{2 \mathrm{~g}}{ }^{6}, S=0\right)$ of [Fe(II)(R-trz) 3 @ Nafion $\left(\mathrm{R}=\mathrm{H}, \mathrm{NH}_{2}\right)$ are colorless and purple, respectively. In fact, the LS state of $\left[\mathrm{Fe}(\mathrm{II})\left(\mathrm{R}-\mathrm{trz}_{3}\right] @\right.$ Nafion shows a broad band in the visible region, at about $18,500 \mathrm{~cm}^{-1}$, corresponding to the ${ }^{1} \mathrm{~A}_{1 \mathrm{~g}} \rightarrow{ }^{1} \mathrm{~T}_{1 \mathrm{~g}}$ transition, while the HS state shows a broad band in the near-infrared region, at about $12,500 \mathrm{~cm}^{-1}$, corresponding to the ${ }^{5} \mathrm{~T}_{2 \mathrm{~g}} \rightarrow{ }^{5} \mathrm{E}_{\mathrm{g}}$ transition.

In order to investigate the LIESST effect for [Fe(II)(H-trz) $)_{3} @ N$ afion, we used the LS absorption band corresponding to the ${ }^{1} \mathrm{~A}_{1 \mathrm{~g}} \rightarrow{ }^{1} \mathrm{~T}_{1 \mathrm{~g}}$ transition as a sensitive monitor of the density of the photoexcited HS molecules, $n_{\mathrm{HS}}\left(=1-n_{\mathrm{LS}}\right)$, and investigated the variation of $n_{\mathrm{HS}}$ against the excitation power density $(P)$, temperature $(T)$, and the delay time $(t)$ [29]. The $514.5 \mathrm{~nm}$ line of $\mathrm{Ar}^{+}$ion laser was used as the source of excitation and probe lights. Figure 22 shows the LIESST effect for $\left[\mathrm{Fe}(\mathrm{II})(\mathrm{H}-\mathrm{trz})_{3}\right] @$ Nafion. The photoexcitation was performed at $5 \mathrm{~K}$ (the thick line in Figure 22a) with increasing $P$ stepwise every $255 \mathrm{~s}$. For the weak excitation $\left(P \leq 100 \mathrm{~W} / \mathrm{cm}^{2}\right), n_{\mathrm{HS}}$ was essentially unchanged $(\leq 10 \%)$. In the range of 100 to $400 \mathrm{~mW} / \mathrm{cm}^{2}, n_{\mathrm{HS}}$ sharply increased from approximately $10 \%$ to about $60 \%$. According to the variation of $P, n_{\mathrm{HS}}$ promptly changed and reached the steady state under each photoexcitation. In the photostationary state, the conversion to the HS sites balances with their thermal and/or quantum relaxation. Stronger excitation above $P=400 \mathrm{~mW} / \mathrm{cm}^{2}$ hardly affected $n_{\mathrm{HS}}$, which is almost constant from about $60 \%$ to $70 \%$. Such a dependency of $n_{\mathrm{HS}}$ as a function of $P$ becomes insensitive with increasing the measuring temperature, as shown by the thin line in Figure 22a. 

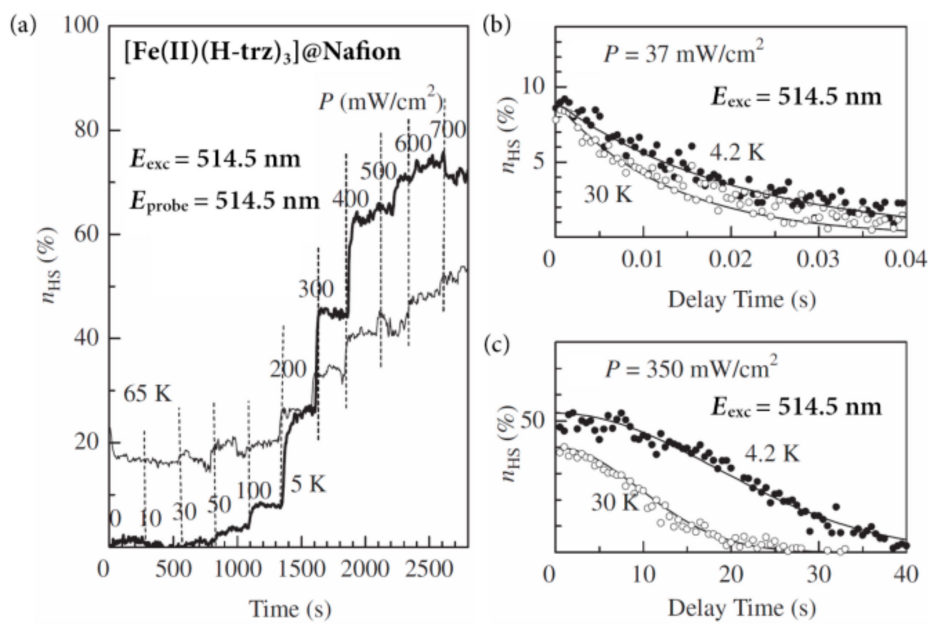

Figure 22. (a) Variation of the density, $n_{\mathrm{HS}}$, of the photoexcited HS molecules in the [Fe(II)(H-trz) 3 ] @Nafion at $5 \mathrm{~K}$ (thick curve) and $65 \mathrm{~K}$ (thin curve) under photoexcitation. Relaxation dynamics of the photogenerated HS molecules for $\left[\mathrm{Fe}(\mathrm{II})(\mathrm{H}-\mathrm{trz})_{3}\right] @ \mathrm{Nafion}$ at $4.2 \mathrm{~K}$ and $30 \mathrm{~K}$ after turning off the excitation light: (b) $P=37 \mathrm{~mW} / \mathrm{cm}^{2}$ and (c) $P=350 \mathrm{~mW} / \mathrm{cm}^{2}$. Solid curves are least-squares-fitting results [29].

At low temperatures, the photogenerated HS fraction as a function of $P$ shows a discontinuous jump when $P$ reaches a threshold value $\left(P_{\mathrm{c}}\right)$, which is found at $\sim 60 \mathrm{~mW} / \mathrm{cm}^{2}$ at $4.2 \mathrm{~K}$. Such threshold behavior is ascribed to the critical nucleation of the photogenerated HS clusters, and the discontinuous jump from the low- $n_{\mathrm{HS}}$ phase to the high- $n_{\mathrm{HS}}$ one corresponds to the phase transition into the condensed state [29]. The lifetime of HS molecules in the high- $n_{\mathrm{HS}}$ region becomes three orders of magnitude longer than that of the isolated molecules, reflecting the elastic interaction between neighboring HS molecules, which looks like a condensation process. Actually, the relaxation process from the condensed state is non-exponential, making a sharp contrast with the conventional exponential decay for non-interacting particles, which is shown in Figure 22b. At low temperatures $(\leq 35 \mathrm{~K})$ and in the high- $P$ region, as shown in Figure 22 , the nonlinear increase in $n_{\mathrm{HS}}$, as well as the non-exponential decay of $n_{\mathrm{HS}}$, suggest the dynamical phase transition into the photoexcited condensed phase, which is schematically shown in Figure 23. The hatched region represents the condensed phase of the photoexcited HS state, which is observed only under photoexcitation, and vanishes if the excitation light is switched off. In other words, this condensed phase is stabilized by the attractive interaction between the HS sites and not by the transformation into a metastable structure.

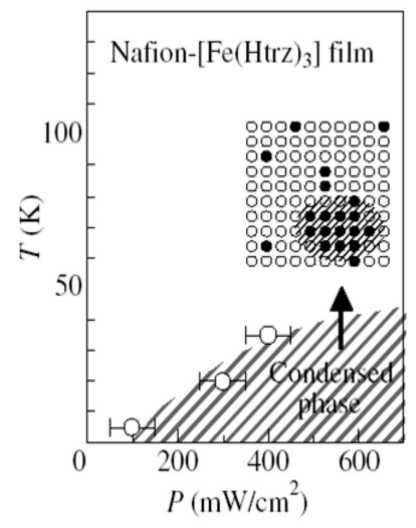

Figure 23. Phase diagram of the $\left[\mathrm{Fe}(\mathrm{II})(\mathrm{Htrz})_{3}\right] @$ Nafion against excitation power density $(P)$ and temperature $(T)$ [29]. The hatched region represents the condensed phase of the photoexcited HS molecules. The inset of closed circles shows the distribution pattern of the photoexcited HS molecules. 


\section{Experimental Procedure}

\subsection{Syntheses}

\subsection{1. $\left[\mathrm{Fe}(\mathrm{II})\left(\mathrm{NH}_{2} \text {-trz }\right)_{3}\right](o-, m-, p \text {-tos })_{2} \cdot x \mathrm{H}_{2} \mathrm{O}$ Synthesis}

Iron powder was dissolved in an aqueous solution of toluenesulfonic acid. Adding an aqueous solution of $\mathrm{NH}_{2}$-trz to the above solution, [Fe(II) $\left.\left(\mathrm{NH}_{2} \text {-trz }\right)_{3}\right](o-, m-, p \text {-tos })_{2} \cdot x \mathrm{H}_{2} \mathrm{O}$ was precipitated immediately. The amount of hydrated water, $x$, was determined by thermogravimetric analysis as $x=2,1.5$, and 1.5 for the $o-, m-, p$-isomers. [Fe(II) $\left.\left(\mathrm{NH}_{2} \text {-trz }\right)_{3}\right](o-, m-, p \text {-abs })_{2} \cdot 2 \mathrm{H}_{2} \mathrm{O}$ was also synthesized likewise. The number of hydrated water molecules was determined by thermogravimetric analysis as 2 for all the $o_{-}, m-, p$-isomers.

\subsection{2. $\left[\mathrm{Fe}(\mathrm{II})\left(\mathrm{NH}_{2}-\mathrm{trz}\right)_{3}\right](\mathrm{SP} 150)_{2} \cdot 2 \mathrm{H}_{2} \mathrm{O}$ Synthesis}

An aqueous solution of SP150 (Japan Photopigment Institute Co., Okayama, Japan) was mixed with the cation-exchange resin (TOYOPEARL 650) adsorbing iron(II) ions, stirred overnight, then filtered off. After evaporating water, $\mathrm{Fe}(\mathrm{SP} 150)_{2}$ was obtained. The methanol solution of $\mathrm{Fe}(\mathrm{II})(\mathrm{SP} 150)_{2}$ was mixed with a methanol solution of $\mathrm{NH}_{2}$-trz. Then, $\left[\mathrm{Fe}(\mathrm{II})\left(\mathrm{NH}_{2} \text {-trz }\right)_{3}\right](\mathrm{SP} 150)_{2}$ precipitated immediately. $\left[\mathrm{Fe}(\mathrm{II})\left(\mathrm{NH}_{2} \text {-trz }\right)_{3}\right](\mathrm{SP} 150)_{2}$ absorbs two crystal water molecules per the formula unit under ambient humidity, which is determined by means of thermogravimetric analysis.

\subsection{3. $\left[\mathrm{Fe}(\mathrm{II})\left(\mathrm{NH}_{2} \text {-trz }\right)_{3}\right]\left(\mathrm{C}_{n} \mathrm{H}_{2 n+1} \mathrm{SO}_{3}\right)_{2} \cdot x \mathrm{H}_{2} \mathrm{O}$ Synthesis}

In the cases of $n=1$ and $n=2$, iron powder was dissolved in an aqueous solution of the alkanesulfonic acid $\mathrm{C}_{n} \mathrm{H}_{2 n+1} \mathrm{SO}_{3} \mathrm{H}$. After evaporating the water, the desired compound precipitated as a bluish powder. Ascorbic acid was used to prevent the partial oxidation of iron(II). The crude product was recrystallized from methanol. In the cases of $n=3-9$, an aqueous solution of $\mathrm{FeSO}_{4} \cdot 7 \mathrm{H}_{2} \mathrm{O}$ was mixed with cation-exchange resin, stirred overnight, then filtered off. The aqueous solution of $\mathrm{C}_{n} \mathrm{H}_{2 n+1} \mathrm{SO}_{3} \mathrm{Na}$ was mixed with the cation-exchange resin absorbing iron(II) ions, stirred overnight, then filtered off. After evaporating the water, the desired compound precipitated. The crude product was recrystallized from methanol. The methanol solution of $\mathrm{Fe}\left(\mathrm{C}_{n} \mathrm{H}_{2 n+1} \mathrm{SO}_{3}\right)_{2} \cdot x \mathrm{H}_{2} \mathrm{O}$ was mixed with the methanol solution of $\mathrm{NH}_{2}$-trz, then $\left[\mathrm{Fe}(\mathrm{II})\left(\mathrm{NH}_{2} \text {-trz }\right)_{3}\right]\left(\mathrm{C}_{n} \mathrm{H}_{2 n+1} \mathrm{SO}_{3}\right)_{2} \cdot x \mathrm{H}_{2} \mathrm{O}$ precipitated immediately as a white powder, and was then filtered off. Because of the hydration, the color of the compound turned to red-purple after a while. The number of crystal water was determined by the thermogravimeter. The value of $x$ is 0.5 for $n=1,2.5$ for $n=2$, and 1.5 for the other compounds.

\subsubsection{SCO Complex Film [Fe(II)(R-trz $\left.)_{3}\right] @ N a f i o n\left(R=H, \mathrm{NH}_{2}\right)$ Synthesis}

The acid form of Nafion 117 was immersed in an aqueous solution of $\mathrm{FeSO}_{4} \cdot 7 \mathrm{H}_{2} \mathrm{O}$. The mobile anions $\left(\mathrm{SO}_{4}{ }^{2-}\right)$ were excluded from the polymer matrix because their ionic charge was identical to that of the fixed ions. After being immersed in the aqueous solution of $\mathrm{FeSO}_{4}$ for $2 \mathrm{~h}$, the film was rinsed in methanol, then it was immersed in a methanol solution of R-trz. One hour later, the film was picked up and washed with methanol, then dried under a nitrogen atmosphere.

\subsection{Measurements}

\subsubsection{Fe K-Edge EXAFS Spectroscopy}

Fe K-edge EXAFS spectra were measured in the conventional transmission mode at BL-10B in the Photon Factory (operation energy of $2.5 \mathrm{GeV}$ and stored current of 400-200 mA) at the High Energy Accelerator Research Organization in Tsukuba, Japan. A water-cooled Si(311) channel-cut crystal was employed as a monochromator. The intensities of the incident and transmitted X-ray were recorded using ionization chambers filled with pure $\mathrm{N}_{2}$. Although the absolute photon energy was not calibrated, the relative photon energies never changed during the measurements within the employed 
energy step $(0.2 \mathrm{eV})$, judging from several glitches appearing in the $I_{0}$ function. The sample was diluted with BN to give a pellet for EXAFS measurements. In order to prevent the desorption of crystal water in the vacuum, the pellet was completely sealed with an adhesive substrate (STYCAST 1266). The Fe K-edge jump was found to be approximately 0.1, while the total absorption coefficient was estimated to be less than 4.0, most of which originated from BN and the adhesive substrate. For the low-temperature measurements, a closed cycle He refrigerator was used and the temperature was measured with a Si diode placed close to the sample. In order to evaluate the back-scattering amplitude and the phase shift, we employed the theoretical standards given by FEFF6 [62]. A model structure constituted of a $\mathrm{Fe}_{5}\left(\mathrm{NH}_{2} \text {-trz }\right)_{12}$ chain cluster was presumed in FEFF6 calculations, where the central iron atom is an X-ray-absorbing atom and all the $\mathrm{H}$ atoms are neglected, therefore there are 77 atoms in total.

\subsubsection{Magnetic Susceptibility Measurements}

The temperature dependence of $\chi_{\mathrm{M}} T$ was measured with an MPMS-5S SQUID magnetometer (Quantum Design, San Diego, CA, USA). Powder samples were sealed in an aluminum capsule to prevent the loss of crystal water on the heating process. The applied field was $0.1 \mathrm{~T}$ or $0.5 \mathrm{~T}$. The temperature was swept in heating and cooling modes in order to examine the thermal hysteresis effect. In compounds showing the thermal hysteresis, the temperature was cycled more than twice.

\subsection{3. ${ }^{57} \mathrm{Fe}$ Mössbauer Spectroscopy}

For ${ }^{57} \mathrm{Fe}$ Mössbauer spectroscopic measurement (Topologic Systems Co., Kanagawa, Japan), ${ }^{57} \mathrm{Co}$ in Rh matrix was used as a Mössbauer source. Powder samples were sealed in an acrylate resin sample holder with silicon grease to prevent the loss of crystal water. The spectra were calibrated by using the six lines of a body-centered cubic iron foil ( $\alpha-\mathrm{Fe})$, the center of which was taken as zero isomer shift. A cryogenic refrigerator set (Iwatani Industrial Gases Co., Osaka, Japan), Cryomini and MiniStat, was used in the temperature range between 10 and $300 \mathrm{~K}$. The spectra were fitted with a MossWinn 3.0 program [63].

\subsubsection{Optical Spectroscopy}

In order to investigate the LIESST effect for $\left[\mathrm{Fe}(\mathrm{II})(\mathrm{H}-\mathrm{trz})_{3}\right] @ \mathrm{Nafion}$, we utilized the LS absorption band corresponding to the ${ }^{1} \mathrm{~A}_{1 \mathrm{~g}} \rightarrow{ }^{1} \mathrm{~T}_{1 \mathrm{~g}}$ transition as a sensitive monitor of the density of photoexcited HS molecules, $n_{\mathrm{HS}}\left(=1-n_{\mathrm{LS}}\right)$, and investigated the variation of $n_{\mathrm{HS}}$ against the excitation power density $(P)$, temperature $(T)$, and the delay time $(t)$. The $514.5 \mathrm{~nm}$ line of $\mathrm{Ar}^{+}$ion laser was used as the source of excitation and probe lights [29]. The power density of the probe light was kept below $0.5 \mathrm{~mW} / \mathrm{cm}^{2}$. The excitation light, which selectively excites the LS state into the HS state, was focused on the sample so that the excitation light $(3 \mathrm{~mm} \varphi)$ completely overlaps the probe light $(1 \mathrm{~mm} \varphi)$.

\section{Conclusions}

In the triazole-bridged iron(II) polymeric chain system, $\left[\mathrm{Fe}(\mathrm{II})(\mathrm{R}-\mathrm{trz})_{3}\right] \mathrm{X}_{2} \cdot x \mathrm{H}_{2} \mathrm{O}$, where $\mathrm{X}$ is the anion, we have controlled the SCO phenomenon by means of characteristic properties of counter anions and crystal water molecules.

With regard to the effect of crystal water on the SCO phenomenon, we prepared [Fe(II) $\left.\left(\mathrm{NH}_{2} \text {-trz }\right)_{3}\right]$ $(p \text {-tos })_{2} \cdot x \mathrm{H}_{2} \mathrm{O}(x=1.5,3.5,5.5$, and 8$)$ and investigated the LS to HS transition. In this system, with increasing the amount of crystal water, $x$, the transition temperature lowers and the thermal hysteresis width becomes narrow.

In order to investigate the effect of counter anions on the SCO phenomenon, we have synthesized $\left[\mathrm{Fe}(\mathrm{II})(\mathrm{R} \text {-trz })_{3}\right] \mathrm{X}_{2} \cdot x \mathrm{H}_{2} \mathrm{O}\left(\mathrm{X}=\right.$ tos and abs). In these systems, $T_{1 / 2}$ and its hysteresis width vary drastically with the structural isomerism, which implies the possibility of photoinduced spin transition by means of the photoisomerization of counter ions. Based on this strategy, we synthesized 
[Fe(II) $\left.\left(\mathrm{NH}_{2} \text {-trz }\right)_{3}\right](\mathrm{SP} 150)_{2} \cdot 2 \mathrm{H}_{2} \mathrm{O}$ and investigated the $\mathrm{SCO}$ phenomenon. In the case where $\mathrm{X}$ is $\mathrm{C}_{n} \mathrm{H}_{2 n+1} \mathrm{SO}_{3}{ }^{-}$, the spin transition temperature $\left(T_{1 / 2}\right)$ increases with increasing the length of the alkyl chain of the counter ion and saturates above $n=5$, which is attributed to the increase in the intermolecular interaction between the alkyl chains of $\mathrm{C}_{n} \mathrm{H}_{2 n+1} \mathrm{SO}_{3}{ }^{-}$, called the fastener effect. The hysteresis width of $\Delta T_{1 / 2}$ decreases with increasing $n$, showing the even-odd effect. Moreover, we developed $\left[\mathrm{Fe}(\mathrm{II})(\mathrm{R}-\mathrm{trz})_{3}\right] @$ Nafion films exhibiting SCO phenomena around room temperature, in which the Nafion membrane behaves as a counter anion as well as a transparent substrate. In this preparation process, it is possible to produce the homogeneous SCO complex film of 300 by $300 \mathrm{~mm}^{2}$ based on Nafion. Moreover, we investigated the LIESST effect for [Fe(II)(H-trz $\left.)_{3}\right] @ N a f i o n$ and observed the condensed photogenerated HS state below $35 \mathrm{~K}$. The lifetime of the photogenerated HS state strongly depends on the intensity of irradiated light.

Acknowledgments: We wish to thank Akio Nakamoto, Yuichi Murakami and Syuji Toyazaki for the development of triazole-bridged iron(II) polymeric chain system, [Fe(II)(R-trz) $\left.)_{3}\right] \mathrm{A} \cdot x \mathrm{H}_{2} \mathrm{O}(\mathrm{A}=$ anion, ion-exchange resin). We also thank to Toshihiko Yokoyama for the measurement and analysis of Fe K-edge EXAFS, and XiaoJun Liu, Yutaka Moritomo, and Arao Nakamura for the investigation of LIESST effect. This work was supported by a Grant-in-Aid for Scientific Research from the Ministry of Education, Culture, Sports, Science and Technology, Japan.

Author Contributions: Norimichi Kojima conceived and directed the project. Akira Sugahara, Hajime Kamebuchi, and Norimichi Kojima synthesized, characterized and measured the SCO materials. Atsushi Okazawa and Masaya Enomoto also contributed to the measurements of magnetic susceptibility and ${ }^{57} \mathrm{Fe}$ Mössbauer spectra. Akira Sugahara, Hajime Kamebuchi, and Norimichi Kojima mainly wrote the manuscript, which was improved by all the authors.

Conflicts of Interest: The authors declare no conflict of interest.

\section{References}

1. Cambi, L.; Gagnasso, A. Iron dithiocarbamates and nitrosodithiocarbamates. Atti. Accad. Naz. Lincei. 1931, 13, 809-813.

2. Gütlich, P.; Goodwin, H.A. Spin Crossover in Transition Metal Compounds I-III; Springer: Berlin/Heidelberg, Germany, 2004.

3. Decurtins, S.; Gütlich, P.; Köhler, C.P.; Spiering, H. Light-induced excited spin state trapping in a transition-metal complex: The hexa-1-propyltetrazole-iron(II) tetrafluoroborate spin-crossover system. Chem. Phys. Lett. 1984, 105, 1-4.

4. Decurtins, S.; Gütlich, P.; Hasselbach, K.M.; Hauser, A.; Spiering, H. Light-induced excited-spin-state trapping in iron(II) spin-Crossover systems. Optical spectroscopic and magnetic susceptibility study. Inorg. Chem. 1985, 24, 2174-2178.

5. Gütlich, P.; Gaspar, A.B.; Garcia, Y. Spin state switching in iron coordination compounds. Beilstein J. Org. Chem. 2013, 9, 342-391. [CrossRef] [PubMed]

6. Krober, J.; Codjovi, E.; Kahn, O.; Groliere, F.; Jay, C. A spin transition system with a thermal hysteresis at room temperature. J. Am. Chem. Soc. 1993, 115, 9810-9811. [CrossRef]

7. Aromí, G.; Barrios, L.A.; Roubeau, O.; Gamez, P. Triazoles and tetrazoles: Prime ligands to generate remarkable coordination materials. Coord. Chem. Rev. 2011, 255, 485-546. [CrossRef]

8. Roubeau, O. Triazole-based one-dimensional spin-crossover coordination polymers. Chem. Eur. J. 2012, 18, 15230-15244. [CrossRef] [PubMed]

9. Jureschi, C.-M.; Linares, J.; Boulmaali, A.; Dahoo, P.R.; Rotaru, A.; Garcia, Y. Pressure and temperature sensors using two spin crossover materials. Sensors 2016, 16, 187. [CrossRef] [PubMed]

10. Kahn, O.; Martinez, C.J. Spin-transition polymers: From molecular materials toward memory devices. Science 1998, 279, 44-48. [CrossRef]

11. Garcia, Y.; Renz, F.; Gütlich, P. LIESST effect in Fe(II) 1,2,4-triazole chains. Curr. Inorg. Chem. 2016, 6, 4-9.

12. Grosjean, A.; Daro, N.; Kauffmann, B.; Kaiba, A.; Létard, J.-F.; Guionneau, P. The 1-D polymeric structure of the $\left[\mathrm{Fe}\left(\mathrm{NH}_{2} \mathrm{trz}\right)_{3}\right]\left(\mathrm{NO}_{3}\right)_{2} \cdot n \mathrm{H}_{2} \mathrm{O}$ (with $\left.n=2\right)$ spin crossover compound proven by single crystal investigations. Chem. Commun. 2011, 47, 12382-12384. [CrossRef] [PubMed] 
13. Armand, F.; Badoux, C.; Bonville, P.; Ruaudel-Teixier, A.; Kahn, O. Langmuir-blodgett films of spin transition iron(II) metalloorganic polymers. 1. Iron(II) complexes of octadecyl-1,2,4-triazole. Langmuir 1995, 11, 3467-3472. [CrossRef]

14. Kuroiwa, K.; Shibata, T.; Sasaki, S.; Ohba, M.; Takahara, A.; Kunitake, T.; Kimizuka, N. Supramolecular control of spin-crossover phenomena in lipophilic Fe(II)-1,2,4-triazole complexes. J. Polym. Sci. Polym. Chem. 2006, 44, 5192-5202. [CrossRef]

15. Fujigaya, T.; Jiang, D.L.; Aida, T. Spin-crossover dendrimers: Generation number-dependent cooperativity for thermal spin transition. J. Am. Chem. Soc. 2005, 127, 5484-5489. [CrossRef] [PubMed]

16. Sonar, P.; Grunert, C.M.; Wei, Y.-L.; Kusz, J.; Gütlich, P.; Schlüter, A.D. Iron(II) spin transition complexes with dendritic ligands, part I. Eur. J. Inorg. Chem. 2008, 10, 1613-1622. [CrossRef]

17. Wei, Y.-L.; Sonar, P.; Grunert, M.; Kusz, J.; Schlüter, A.D.; Gütlich, P. Iron(II) spin-transition complexes with dendritic ligands, part II. Eur. J. Inorg. Chem. 2010, 25, 3930-3941. [CrossRef]

18. Rubio, M.; Hernández, R.; Nogales, A.; Roig, A.; López, D. Structure of a Spin-Crossover Fe(II)-1,2,4-triazole polymer complex dispersed in an isotactic polystyrene matrix. Eur. Polym. J. 2011, 47, 52-60. [CrossRef]

19. Lee, S.-W.; Lee, J.-W.; Jeong, S.-H.; Park, I.-W.; Kim, Y.-M.; Jin, J.-I. Processable magnetic plastics composites-Spin crossover of PMMA/Fe(II)-complexes composites. Synth. Met. 2004, 142, 243-249. [CrossRef]

20. Gural'skiy, I.A.; Quintero, C.M.; Costa, J.S.; Demont, P.; Molnár, G.; Salmon, L.; Shepherd, H.J.; Bousseksou, A. Spin crossover composite materials for electrothermomechanical actuators. J. Mater. Chem. C 2014, 2, 2949-2955. [CrossRef]

21. Nakamoto, A.; Ono, Y.; Kojima, N.; Matsumura, D.; Yokoyama, T. Spin crossover complex film, $\left[\mathrm{Fe}^{\mathrm{II}}\left(\mathrm{H}-\mathrm{trz}_{3}\right]\right.$-nafion, with a spin transition around room temperature. Chem. Lett. 2003, 32, 336-337. [CrossRef]

22. Nakamoto, A.; Ono, Y.; Kojima, N.; Matsumura, D.; Yokoyama, T.; Liu, X.J.; Moritomo, Y. Spin transition and its photo-induced effect in spin crossover complex film based on [Fe(II)(trz) 3 ]. Synth. Met. 2003, 137, 1219-1220. [CrossRef]

23. Nakamoto, A.; Kamebuchi, H.; Enomoto, M.; Kojima, N. Study on the spin crossover transition and glass transition for Fe(II) complex film, [Fe(II)(H-triazole) $\left.{ }_{3}\right] @ N a f i o n$, by means of Mössbauer spectroscopy. Hyperfine Interact. 2012, 205, 41-45. [CrossRef]

24. Sugahara, A.; Enomoto, M.; Kojima, N. Isomerization effect of counter anion on the spin crossover transition in $\left[\mathrm{Fe}\left(4-\mathrm{NH}_{2} \mathrm{trz}\right)_{3}\right]\left(\mathrm{CH}_{3} \mathrm{C}_{6} \mathrm{H}_{4} \mathrm{SO}_{3}\right)_{2} \cdot n \mathrm{H}_{2} \mathrm{O}$. J. Phys. Conf. Ser. 2010, 217, 12128. [CrossRef]

25. Toyazaki, S.; Nakanishi, M.; Komatsu, T.; Kojima, N.; Matsumura, D.; Yokoyama, T. Control of $T_{C}$ by isomerization of counter anion in $\mathrm{Fe}(\mathrm{II})$ spin crossover complexes, $\left[\mathrm{Fe}\left(4-\mathrm{NH}_{2} \mathrm{trz}\right)_{3}\right]\left(\mathrm{R}_{-} \mathrm{SO}_{3}\right)_{2}$. Synth. Met. 2001, 121, 1794-1795. [CrossRef]

26. Toyazaki, S. The Control of Spin-Crossover Behavior of Fe(II) Triazole Complexes. Master's Thesis, The University of Tokyo, Tokyo, Japan, 2000.

27. Kamebuchi, H.; Nakamoto, A.; Yokoyama, T.; Kojima, N. Fastener effect on uniaxial chemical pressure for one-dimensional spin-crossover system, $\left[\mathrm{Fe}^{\mathrm{II}}\left(\mathrm{NH}_{2} \text {-trz }\right)_{3}\right]\left(\mathrm{C}_{n} \mathrm{H}_{2 n+1} \mathrm{SO}_{3}\right)_{2} \cdot x \mathrm{H}_{2} \mathrm{O}$ : Magnetostructural correlation and ligand field analysis. Bull. Chem. Soc. Jpn. 2015, 88, 419-430. [CrossRef]

28. Absmeier, A.; Bartel, M.; Carbonera, C.; Jameson, G.N.L.; Weinberger, P.; Caneschi, A.; Mereiter, K.; Létard, J.-F.; Linert, W. Both spacer length and parity influence the thermal and light-induced properties of iron(II) $\alpha, \omega$-bis(tetrazole-1-yl)alkane coordination polymers. Chem. Eur. J. 2006, 12, 2235-2243. [CrossRef] [PubMed]

29. Liu, X.J.; Moritomo, Y.; Kawamoto, T.; Nakamoto, A.; Kojima, N. Dynamical phase transition in a spin-crossover complex. J. Phys. Soc. Jpn. 2003, 72, 1615-1618. [CrossRef]

30. Hostettler, M.; Törnroos, K.W.; Chernyshov, D.; Vangdal, B.; Bürgi, H.-B. Challenges in engineering spin crossover: Structures and magnetic properties of six alcohol solvates of iron(II) tris(2-picolylamine) dichloride. Angew. Chem. Int. Ed. 2004, 43, 4589-4594. [CrossRef] [PubMed]

31. Nakamoto, T.; Bhattacharjee, A.; Sorai, M. Cause for unusually large thermal hysteresis of spin crossover in [Fe(2-pic) $\left.{ }_{3}\right] \mathrm{Cl}_{2} \cdot \mathrm{H}_{2} \mathrm{O}$. Bull. Chem. Soc. Jpn. 2004, 77, 921-932. [CrossRef]

32. Codjovi, E.; Sommier, L.; Kahn, O.; Jay, C. A spin transition molecular material with an exceptionally large thermal hysteresis loop at room temperature. New J. Chem. 1996, 20, 503-505. 
33. Toyazaki, S.; Murakami, Y.; Komatsu, T.; Kojima, N.; Yokoyama, T. Study on the spin-crossover system for [Fe(4-NH $\mathrm{N}_{2}$ trz $\left.)_{3}\right]\left(\mathrm{p}_{-} \mathrm{CH}_{3} \mathrm{C}_{6} \mathrm{H}_{4} \mathrm{SO}_{3}\right)_{2} \cdot n \mathrm{H}_{2} \mathrm{O}$. Mol. Cryst. Liq. Cryst. 2000, 343, 175-180. [CrossRef]

34. Stern, E.A. Theory of EXAFS. In X-ray Absorption: Principles, Applications, Techniques of EXAFS, SEXAFS and XANES; Koningsberger, D.C., Prins, R., Eds.; Wiley: New York, NY, USA, 1988; pp. 3-52.

35. Michalowicz, A.; Moscovici, J.; Ducourant, B.; Cracco, D.; Kahn, O. EXAFS and X-ray powder diffraction studies of the spin transition molecular materials $\left[\mathrm{Fe}(\mathrm{Htrz})_{2}(\operatorname{trz})\right]\left(\mathrm{BF}_{4}\right)$ and $\left[\mathrm{Fe}(\mathrm{Htrz})_{3}\right]\left(\mathrm{BF}_{4}\right)_{2} \cdot \mathrm{H}_{2} \mathrm{O}(\mathrm{Htrz}=$ 1,2,4-4H-triazole; trz = 1,2,4-triazolato). Chem. Mater. 1995, 7, 1833-1842. [CrossRef]

36. Soyer, H.; Mingotaud, C.; Boillot, M.-L.; Delhaes, P. Spin-crossover complex stabilized on a formamide/water subphase. Thin Solid Films 1998, 327-329, 435-438. [CrossRef]

37. Lavrenova, L.G.; Yudina, N.G.; Ikorskii, V.N.; Varnek, V.A.; Oglezneva, I.M.; Larionov, S.V. Spin-crossover and thermochromism in complexes of iron(II) iodide and thiocyanate with 4-amino-1,2,4-triazole. Polyhedron 1995, 14, 1333-1337. [CrossRef]

38. Bausk, N.V.; Érenburg, S.B.; Mazalov, L.N.; Lavrenova, L.G.; Ikorskii, V.N. Electronic and spatial structure of spin transition iron(II) tris(4-amino-1,2,4-triazole) nitrate and perchlorate complexes. J. Struct. Chem. 1994, 35, 509-516. [CrossRef]

39. Varnek, V.A.; Lavrenova, L.G. Mössbauer study of the influence of ligands and anions of the second coordination sphere in Fe(II) complexes with 1,2,4-triazole and 4-amino-1,2,4-triazole on the temperature of the ${ }^{1} A_{1} \leftrightarrows{ }^{5} T_{2}$ spin transitions. J. Struct. Chem. 1995, 36, 104-111. [CrossRef]

40. Van Koningsbruggen, P.J.; Garcia, Y.; Codjovi, E.; Lapouyade, R.; Kahn, O.; Fournès, L.; Rabardel, L. Non-classical Fe ${ }^{\mathrm{II}}$ spin-crossover behaviour in polymeric iron(II) compounds of formula [Fe( $\left.\left(\mathrm{NH}_{2} \operatorname{trz}\right)_{3}\right] \mathrm{X}_{2} \cdot x \mathrm{H}_{2} \mathrm{O}\left(\mathrm{NH}_{2} \operatorname{trz}=4\right.$-amino-1,2,4-triazole; $\mathrm{X}=$ derivatives of naphthalene sulfonate $)$. J. Mater. Chem. 1997, 7, 2069-2075. [CrossRef]

41. Garcia, Y.; van Koningsbruggen, P.J.; Lapouyade, R.; Rabardel, L.; Kahn, O.; Wieczorek, M.; Bronisz, R.; Ciunik, Z.; Rudolf, M.F. Synthesis and spin-crossover characteristics of polynuclear 4-(2'-hydroxy-ethyl)-1,2,4-triazole Fe(II) molecular materials. C. R. Acad. Sci. Ser. IIC Chem. 1998, 1, 523-532. [CrossRef]

42. Erenburg, S.B.; Bausk, N.V.; Lavrenova, L.G.; Varnek, V.A.; Mazalov, L.N. Relation between electronic and spatial structure and spin-transition parameters in chain-like Fe(II) compounds. Solid State Ion. 1997, 101-103, 571-577. [CrossRef]

43. Dîrtu, M.M.; Rotaru, A.; Gillard, D.; Linares, J.; Codjovi, E.; Tinant, B.; Garcia, Y. Prediction of the spin transition temperature in $\mathrm{Fe}^{\mathrm{II}}$ one-dimensional coordination polymers: An anion based database. Inorg. Chem. 2009, 48, 7838-7852. [CrossRef] [PubMed]

44. Jenkins, H.D.B.; Roobottom, H.K.; Passmore, J.; Glasser, L. Relationships among Ionic Lattice Energies, Molecular (Formula Unit) Volumes, and Thermochemical Radii. Inorg. Chem. 1999, 38, 3609-3620. [CrossRef] [PubMed]

45. Bushuev, M.B.; Lavrenova, L.G.; Shvedenkov, Y.G.; Varnek, V.A.; Sheludyakova, L.A.; Volkov, V.V.; Larionov, S.V. Complexes $\mathrm{Fe}(\mathrm{HTrz})_{3} \mathrm{~B}_{10} \mathrm{H}_{10} \cdot \mathrm{H}_{2} \mathrm{O}$ and $\mathrm{Fe}\left(\mathrm{NH}_{2} \mathrm{Trz}\right)_{3} \mathrm{~B}_{10} \mathrm{H}_{10} \cdot \mathrm{H}_{2} \mathrm{O}(\mathrm{HTrz}=1$,2,4-triazole and $\mathrm{NH}_{2} \mathrm{Trz}=4$-amino-1,2,4-triazole). The spin transition ${ }^{1} A_{1} \leftrightarrows{ }^{5} T_{2}$ in $\mathrm{Fe}(\mathrm{HTrz})_{3} \mathrm{~B}_{10} \mathrm{H}_{10} \cdot \mathrm{H}_{2} \mathrm{O}$. Russ. J. Coord. Chem. 2008, 34, 190-194. [CrossRef]

46. Urakawa, A.; van Beek, W.; Monrabal-Capilla, M.; Galán-Mascarós, J.R.; Palin, L.; Milanesio, M. Combined, modulation enhanced $\mathrm{X}$-ray powder diffraction and raman spectroscopic study of structural transitions in the spin crossover material [Fe(Htrz $\left.)_{2}(\operatorname{trz})\right]\left(\mathrm{BF}_{4}\right)$. J. Phys. Chem. C. 2011, 115, 1323-1329. [CrossRef]

47. Grosjean, A.; Négrier, P.; Bordet, P.; Etrillard, C.; Mondieig, D.; Pechev, S.; Lebraud, E.; Létard, J.-F.; Guionneau, P. Crystal structures and spin crossover in the polymeric material $\left[\mathrm{Fe}(\mathrm{Htrz})_{2}(\mathrm{trz})\right]\left(\mathrm{BF}_{4}\right)$ including coherent-domain size reduction effects. Eur. J. Inorg. Chem. 2013, 2013, 796-802. [CrossRef]

48. Gütlich, P.; Gaspar, A.B.; Ksenofontov, V.; Garcia, Y. Pressure effect studies in molecular magnetism. J. Phys. Condens. Matter 2004, 16, S1087-S1108. [CrossRef]

49. Gütlich, P.; Ksenofontov, V.; Gaspar, A.B. Pressure effect studies on spin crossover systems. Coord. Chem. Rev. 2005, 249, 1811-1829. [CrossRef]

50. Gütlich, P.; Gaspar, A.B.; Garcia, Y.; Ksenofontov, V. Pressure effect studies in molecular magnetism. C. R. Chim. 2007, 10, 21-36. [CrossRef]

51. Klokishner, S.; Linares, J.; Varret, F. Effect of hydrostatic pressure on phase transitions in spin-crossover 1D systems. Chem. Phys. 2000, 255, 317-323. [CrossRef] 
52. Bausk, N.V.; Érenburg, S.B.; Lavrenova, L.G.; Mazalov, L.N. EXAFS study of spin transition effect on the spatial and electronic structure of Fe(II) complexes with triazoles. J. Struct. Chem. 1995, 36, 925-931. [CrossRef]

53. Erenburg, S.B.; Bausk, N.V.; Varnek, V.A.; Lavrenova, L.G. Influence of the electronic and spatial structure parameters on the spin-transition temperature in unusual chain iron(II) complexes. J. Magn. Magn. Mater. 1996, 157-158, 595-596. [CrossRef]

54. Kojima, N.; Murakami, Y.; Komatsu, T.; Yokoyama, T. EXAFS study on the spin-crossover system, $\left[\mathrm{Fe}\left(4-\mathrm{NH}_{2} \text { trz }\right)_{3}\right]\left(\mathrm{R}_{-} \mathrm{SO}_{3}\right)_{2}$. Synth. Met. 1999, 103, 2154. [CrossRef]

55. Murakami, Y.; Komatsu, T.; Kojima, N. Control of Tc and spin bistability in the spin-crossover system, $\left[\mathrm{Fe}\left(4-\mathrm{NH}_{2} \text { trz }\right)_{3}\right]\left(\mathrm{R}_{-} \mathrm{SO}_{3}\right)_{2}$. Synth. Met. 1999, 103, 2157-2158. [CrossRef]

56. Kojima, N.; Toyazaki, S.; Itoi, M.; Ono, Y.; Aoki, W.; Kobayashi, Y.; Seto, M.; Yokoyama, T. Search on multi-functional properties of spin-crossover system. Mol. Cryst. Liq. Cryst. 2002, 376, 567-574. [CrossRef]

57. Hayami, S.; Gu, Z.-Z.; Einaga, Y.; Kobayashi, Y.; Ishikawa, Y.; Yamada, Y.; Fujishima, A.; Sato, O. A novel LIESST iron(II) complex exhibiting a high relaxation temperature. Inorg. Chem. 2001, 40, 3240-3242. [CrossRef] [PubMed]

58. Bonhommeau, S.; Molnár, G.; Galet, A.; Zwick, A.; Real, J.-A.; McGarvey, J.J.; Bousseksou, A. One shot laser pulse induced reversible spin transition in the spin-crossover complex $\left[\mathrm{Fe}\left(\mathrm{C}_{4} \mathrm{H}_{4} \mathrm{~N}_{2}\right)\left\{\mathrm{Pt}(\mathrm{CN})_{4}\right\}\right]$ at room temperature. Angew. Chem. Int. Ed. 2005, 44, 4069-4073. [CrossRef] [PubMed]

59. Hellel, W.; Ould Hamouda, A.; Degert, J.; Létard, J.F.; Freysz, E. Switching of spin-state complexes induced by the interaction of a laser beam with their host matrix. Appl. Phys. Lett. 2013, 103, 143304. [CrossRef]

60. Gallé, G.; Etrillard, C.; Degert, J.; Guillaume, F.; Létard, J.F.; Freysz, E. Study of the fast photoswitching of spin crossover nanoparticles outside and inside their thermal hysteresis loop. Appl. Phys. Lett. 2013, 102, 63302. [CrossRef]

61. Vos, G.; De Graaff, R.A.G.; Haasnoot, J.G.; van der Kraan, A.M.; De Vaal, P.; Reedijk, J. Crystal structure at 300 and $105 \mathrm{~K}$, magnetic properties and Mössbauer spectra of bis(triaquatris(4-ethyltriazole- $N^{1}$ )iron(II)$\left.N^{2}, N^{2}{ }^{\prime}, N^{2 \prime \prime}\right)$ iron(II) hexakis(trifluoromethanesulfonate). A linear, trinuclear iron(II) compound, showing a unique high-spin-low-spin transition of the central iron atom. Inorg. Chem. 1984, 23, 2905-2910.

62. Zabinsky, S.I.; Rehr, J.J.; Ankudinov, A.; Albers, R.C.; Eller, M.J. Multiple-scattering calculations of X-ray-absorption spectra. Phys. Rev. B 1995, 52, 2995-3009. [CrossRef]

63. Klencsár, Z. MossWinn-Mössbauer Spectrum Analysis and Database Software. Available online: http: / / www.mosswinn.com/ (accessed on 18 July 2017). 